\title{
Decreases in Energy and Increases in Phase Locking of Event-Related Oscillations to Auditory Stimuli Occur during Adolescence in Human and Rodent Brain
}

\author{
Cindy L. Ehlers Derek N. Wills Anita Desikan Evelyn Phillips James Havstad
}

Department of Molecular and Cellular Neuroscience, The Scripps Research Institute, La Jolla, Calif., USA

\author{
Key Words \\ Electroencephalogram · Event-related oscillation . \\ Event-related potential · Phase locking index · \\ Adolescence $\cdot$ Time series analysis
}

\begin{abstract}
Synchrony of phase (phase locking) of event-related oscillations (EROs) within and between different brain areas has been suggested to reflect communication exchange between neural networks and as such may be a sensitive and translational measure of changes in brain remodeling that occur during adolescence. This study sought to investigate developmental changes in EROs using a similar auditory event-related potential (ERP) paradigm in both rats and humans. Energy and phase variability of EROs collected from 38 young adult men (aged 18-25 years), 33 periadolescent boys (aged 10-14 years), 15 male periadolescent rats [at postnatal day (PD) 36] and 19 male adult rats (at PD103) were investigated. Three channels of ERP data (frontal cortex, central cortex and parietal cortex) were collected from the humans using an 'oddball plus noise' paradigm that was presented under passive (no behavioral response required) conditions in the periadolescents and under active conditions (where each subject was instructed to depress a counter each time he detected an infrequent target tone) in adults and adolescents. ERPs were recorded in rats using only the passive paradigm.
\end{abstract}

In order to compare the tasks used in rats to those used in humans, we first studied whether three ERO measures [energy, phase locking index (PLI) within an electrode site and phase difference locking index (PDLI) between different electrode sites] differentiated the 'active' from 'passive' ERP tasks. Secondly, we explored our main question of whether the three ERO measures differentiated adults from periadolescents in a similar manner in both humans and rats. No significant changes were found in measures of ERO energy between the active and passive tasks in the periadolescent human participants. There was a smaller but significant increase in PLI but not PDLI as a function of active task requirements. Developmental differences were found in energy, PLI and PDLI values between the periadolescents and adults in both the rats and the human participants. Neuronal synchrony as indexed by PLI and PDLI was significantly higher to the infrequent (target) tone compared to the frequent (nontarget) tone in all brain sites in all of the regions of interest time-frequency intervals. Significantly higher ERO energy and significantly lower synchrony was seen in the periadolescent humans and rats compared to their adult counterparts. Taken together these findings are consistent with the hypothesis that adolescent remodeling of the brain includes decreases in energy and increases in synchrony over a wide frequency range both within and between neuronal networks and that these effects are conserved over evolution.

(c) 2014 S. Karger AG, Base

\section{KARGER}

E-Mail karger@karger.com

www.karger.com/dne (c) 2014 S. Karger AG, Basel

$0378-5866 / 14 / 0364-0175 \$ 39.50 / 0$
Dr. C.L. Ehlers

The Scripps Research Institute

10550 North Torrey Pines Road, SP30-1501

La Jolla, CA 92037 (USA)

E-Mail cindye@scripps.edu 


\section{Introduction}

Adolescence is a critical time period when physical, sexual, cognitive, emotional and social maturation occur [1]. While there has been a tendency to define adolescence by endocrine events such as puberty, it actually involves changes in the brain that may occur in a separate time frame from the endocrine events associated with puberty [2]. During adolescence, there are major changes that occur in brain morphology including the selective removal of $40-50 \%$ of the synapses (synaptic pruning) in cortical and subcortical brain regions [3-6], continued myelination of cortical regions [7-9] and dramatic changes in neurotransmitter levels [10-15] as well as receptor levels and their sensitivity $[4,12]$.

The alterations in neurobiological organization and behavior seen during adolescence appear to have been notably conserved during evolution with a number of similarities seen across mammalian species [16]. It has been suggested to encompass the entire second decade of life (10-20 years) in humans [16]. In the rat it has been suggested that the periadolescent period may, as a conservative estimate, span postnatal days (PD) 28-42 [1719].

The global behavioral changes seen during adolescent development most likely require the integration of a number of functional neuronal areas distributed over the brain that are in constant interaction with each other. It has been suggested that such large-scale integration and communication within the brain could be mediated by groups of neurons that oscillate within a specific frequency range and enter into precise phase locking, or synchrony, over a limited period of time [20-22]. Measures of neuronal phase synchrony may therefore be a sensitive way to measure the effects of developmental changes on local and global neural networks in humans and rats.

Event-related potentials (ERPs) are a series of negative and positive voltage deflections of the electroencephalogram (EEG) that are time locked typically to either sensory or cognitive events and can be recorded in both humans and animals. It has been suggested that the stimuli that evoke ERP components influence oscillatory changes within the dynamics of ongoing EEG rhythms [23-30]. This synchronization or enhancement of ongoing EEG oscillations by a time-locked cognitive and/or sensory process is termed an event-related oscillation (ERO) [3133]. EROs are thought to arise by a 'phase re-ordering', or realignment, of the background EEG in several frequency bands $[34,35]$. Phase locking of EROs can be measured in both humans $[22,33]$ and, more recently, in rodent models [36-39], allowing for translational studies to be conducted.

The present study was conducted to further explore whether differences exist in ERO energy (the square of the output magnitude of the time-frequency transform of the EEG) and phase synchrony (phase locking) between periadolescents and adults in rats and to directly compare those findings to human data. We predicted that over periadolescent development, the remodeling of neuronal circuits produced by pruning and increased myelination could theoretically result in an increase in the synchrony or phase locking of neurons both within a neuronal population and between neuronal populations. Evidence for this hypothesis has been demonstrated previously in human studies [40]. Our study is unique in that we used a similar auditory ERP paradigm in male rats and male humans in order to explore effects of development during the periadolescent-adult period on energy and phase locking of EROs in specific frequency bands. The advantage of this type of 'translational' research is that it allows for the use of electrophysiological measures, which have known clinical correlates in humans, to be used in rodent species where the mechanisms underlying the generation of those measures can be more readily explored using techniques such as genetic modification, molecular biology and behavioral investigations.

In our study two auditory 'oddball plus noise' paradigms were used to generate EROs - one that required responding to the infrequently presented tone ('active' task, used in periadolescent and adult humans) and one that did not require any responses to the tones ('passive' task, used in rats and periadolescent humans). The use of passive tasks are important because they can be used in human participants who may be too young or have cognitive/behavioral challenges that preclude them from being able to adequately respond to the task requirements [41]. Secondly, passive tasks are important in animal research in circumstances where it is not possible to present the stimuli, and train the animal to respond to the stimuli, in a similar manner to humans without using food restriction/food rewards, which presumably have different motivational concomitants.

The first objective of the present investigation was to determine whether ERO measures differentiated active from passive ERP tasks in humans. This question was explored in order to better interpret data in humans and rats since the rats were assessed using a passive paradigm. Secondly, we assessed whether ERO measures of energy and synchrony differentiated adults from periadolescents in both the rats and the humans. 


\section{Experimental Procedures}

\section{Human Participants}

Young Adult Participants

Males between the ages of 18 and 25 years were recruited using a combination of venue-based method and a respondent-driven procedure that has been described elsewhere [42]. Telephone screening with research staff was used to complete a questionnaire $[43,44]$ which was used to select individuals who met eligibility for the study. All participants signed informed consent, and the study was approved by the Scripps Research Institute Internal Review Board. Participants were excluded from further evaluation if they met diagnostic criteria for alcohol or other substance dependence, or other major Axis I psychiatric disorders according to criteria outlined in the third edition of the Diagnostic and Statistical Manual of Mental Disorders [45]. Participants were also excluded from this study if they were taking prescribed medication or had any major medical condition as described previously [42, 46, 47]. Participants were instructed not to use alcohol or any other drugs for 3 days prior to testing. Records from 38 of the participants were still available on readable media and were used in the present analyses. EEG/ERP and ERO responses to alcohol challenge in these participants have been reported previously [42, 46, 47]. Data in the present report included only ERO responses to placebo, for comparison to the periadolescent sample.

\section{Periadolescent Participants}

Two groups of periadolescent children (aged 10-14 years) were recruited as described previously [48-52]. Both groups were recruited from the community and individual informed consent was obtained from one biological parent or legal guardian. Participants were excluded if they were taking any prescribed medication or had any major medical or psychiatric/developmental disorder. Records from 31 of the participants were still available on readable media and were used in the present analyses. Baseline EEG and ERP responses to auditory stimuli in these individuals have been reported previously $[48,49]$. Data in the present report included only ERO responses, for comparison to the young adult participants.

\section{ERP Collection and Analyses in Human Subjects}

Young Adult Participants

Seven channels of ERP data [frontal cortex (FZ), central cortex (CZ), parietal cortex (PZ), F3, F4, F7, F8 and referenced to linked earlobes with a forehead ground, international 10-20 system] were obtained by using gold-plated electrodes with impedance held below 5,000 $\Omega$. An electrode placed left lateral infraorbitally and referenced to the left earlobe was used to monitor both horizontal and vertical eye movement. ERP signals were recorded on a Nihon-Kohden polygraph (sensitivity $7 \mu \mathrm{V} / \mathrm{mm}$, time constant $0.1 \mathrm{~s}, 35-\mathrm{Hz}$ low-pass filter). Signals were transferred to a computer and digitized at a rate of $256 \mathrm{~Hz}$. The EEG amplifier input range corresponded to the full range of the 12-bit analog-to-digital converter was about $\pm 250 \mu \mathrm{V}$. Periodic calibration results were used to scale the digitized EEG to microvolts. Auditory stimuli and ERPs were elicited using an oddball plus noise paradigm. The acoustic parameters were three square wave tones (rise/fall times, $1 \mathrm{~ms}$ ): a frequent tone ( $50 \mathrm{~ms}, 2 \mathrm{kHz}, 70 \mathrm{~dB} \mathrm{SPL}$ ) presented on $83 \%$ of the trials $(\mathrm{n}=200)$, an infrequent tone $(50 \mathrm{~ms}, 2 \mathrm{kHz}, 80 \mathrm{~dB} \mathrm{SPL})$ presented on $10.4 \%$ of the trials $(n=25)$, and a noise burst $(50 \mathrm{~ms}$, noise, $80 \mathrm{~dB}$ SPL) presented on $6.3 \%$ of the trials $(\mathrm{n}=15)$. Each subject was hearing tested prior to the recording to ensure that he had no trouble easily identifying the three different tones. Infrequent tones were interspersed with frequent tones so that no two rare tones occurred consecutively. A noise burst was substituted for an infrequent tone every 12 trials to avoid habituation to the infrequent tone. The digitizing epoch was $1 \mathrm{~s}$ and an intertrial interval of $0.5-1.0 \mathrm{~s}$ was used. The ERP trials were digitized at a rate of $256 \mathrm{~Hz}$. The total number of trials in each recording session was 240. These stimulus characteristics have been used extensively in our laboratory and have been described previously [42, 46, 53]. Each subject was instructed to depress a counter each time he detected an infrequent (target) tone. Individual trials containing excessive eye movement artifact as well as trials where the EEG exceeded $250 \mu \mathrm{V}$ ( $<5 \%$ of the trials) were eliminated.

\section{Periadolescent Participants}

In the first set of periadolescent participants $(n=19)$ [49] seven channels of ERP data (FZ, CZ, PZ, F3, F4, F7, F8 and referenced to linked earlobes with a forehead ground, international 10-20 system) were obtained by using gold-plated electrodes with impedance held below 5,000 $\Omega$. An electrode placed left lateral infraorbitally and referenced to the left earlobe was used to monitor both horizontal and vertical eye movement. ERP recording signals were amplified (time constant $0.1 \mathrm{~s}, 35-\mathrm{Hz}$ low-pass filter) using a Nihon-Kohden EEG machine and transferred to a computer for digitization. Auditory stimuli and ERPs were elicited using an oddball plus noise paradigm identical to that used in the adults and described previously [49]. In the second set of periadolescent participants $(n=12)$, recordings were obtained using an electrode cap. Unipolar recordings from FZ, CZ and PZ were referenced to linked earlobes. The auditory stimuli and ERPs were elicited using a passive oddball plus noise paradigm identical to the one used for the first set of periadolescent participants; however, the noise tone was $20 \mathrm{~dB}$ louder and the participants were not asked to respond to any of the stimuli.

\section{Animal Subjects}

The experimental subjects were 15 male periadolescent (PD23 on arrival, weighing 58-79 g) and 19 male adult (PD90 on arrival, weighing 351-387 g) Wistar rats. At least 1 week prior to the electrophysiological recordings the rats were surgically prepared with screw electrodes placed in the skull overlying the frontal (adults: $\mathrm{AP}+1.5, \mathrm{ML} \pm 3.0$; periadolescents: $\mathrm{AP}+1.5, \mathrm{ML} \pm 2.0$ ), parietal lobe (adults: $\mathrm{AP}-4.5, \mathrm{ML} \pm 4.5$; periadolescents: $\mathrm{AP}-4.0, \mathrm{ML}$ $\pm 3.5)$, and an electrode placed over the cerebellum was used as ground. Two electromyography wire electrodes were also inserted into the rats' neck muscles on the right and left. The rats were anesthetized with isoflurane and atropine $(0.03 \mathrm{ml}$ for periadolescents and $0.06 \mathrm{ml}$ for adults, subcutaneously) was coadministered to minimize respiratory suppression during the surgical procedures. Electromyography and EEG electrode connections were made to an Amphenol 5-pin connector (adult rats) or were assembled into a custom 5-pin cap (for the periadolescent rats), and the assembly was anchored to the skull with dental acrylic and anchor screws. All the animals were pair-housed in standard plastic cages on a 12-hour light/dark cycle (lights on at 8.00 a.m.) and food and water were provided ad libitum. All experimental protocols were approved by the Institutional Animal Care and Use Committee at the Scripps Research Institute and were consistent 
with the guidelines of the NIH Guide for the Care and Use of Laboratory Animals.

\section{ERP Collection and Analyses in Animal Subjects}

ERPs were elicited by auditory stimuli that were presented through a small speaker centered approximately $70 \mathrm{~cm}$ above the rat's head. Electrophysiological recordings were made in the periadolescent rats at PD33-39; the adult rats were recorded on PD100-106. ERPs were elicited by an acoustic oddball plus noise paradigm identical to the passive paradigm described above for the periadolescent human participants. Signals were transferred to a $\mathrm{PC}$ and digitized at a rate of $256 \mathrm{~Hz}$. The EEG amplifier in put range corresponding to the full range of the 12-bit analog-to-digital converter was about $\pm 250 \mu \mathrm{V}$. Periodic calibration results were used to scale the digitized EEG to microvolts.

\section{ERO, Phase Locking Index and Phase Difference Locking Index} Analyses

ERO energy (peak magnitude of the $\mathrm{S}$ transform output, squared, in a time-frequency region of interest, ROI), phase locking index (PLI) and phase difference locking index (PDLI) analyses were accomplished from the same data sets that were used to generate ERP data reported in four previous publications in humans $[42,48,49,54]$ and unpublished data in the rats. Methods for these analyses have been described in detail elsewhere [39, 47].

The ERO trials were digitized at a rate of $256 \mathrm{~Hz}$. Trials containing excessive artifact were eliminated prior to averaging $(<5 \%$ of the trials). An artifact rejection program was utilized to eliminate individual trials in which the EEG exceeded $\pm 400 \mu \mathrm{V}$. Data from single trials generated by the stimuli were entered into the timefrequency analyses algorithm. The $S$ transform, a generalization of the Gabor transform [55], was used [56].

$$
S\left[j T, \frac{n}{N T}\right]=\sum_{m=0}^{N-1} H\left[\frac{m+n}{N T}\right] e^{\frac{-2 \pi^{2} m^{2}}{n^{2}}} e^{\frac{i 2 \pi m j}{N}} \quad n \neq 0
$$

The $S$ transform mathematically resembles the continuous wavelet transform but it uses Gaussian windows which do not meet a requirement of wavelet analysis, and it includes a 'phase correction' that is not part of wavelet analysis. The actual use of the $S$ transform was simplified by performing first a forward Fourier transform of the time series and then, for each frequency of the Fourier transform, summing the results of multiplication by a set of Fourier transforms of Gaussian windows of varying width and finally, for each of these sums, taking the inverse Fourier transform. The equation for calculation of the $S$ transform of discrete time series $h(k T)$ at time $j T$ and frequency $n / N T$ is where $T$ is the sample period of the discrete time series, $j$ is the sample index, $N$ is the number of samples in the time series, $n$ is the frequency index, and $H[]$ is the Fourier spectrum of the discrete time series. The $S$ transform results in a time-frequency representation of the data. The exact code we used is a C language, $S$-transform subroutine available from the NIMH MEG Core Facility website (http:// kurage.nimh.nih.gov/meglab/). This code is specifically for use with real-time series, so it sets the input imaginary values, required by the $S$ transform, to zero, and it always uses the Hilbert transform so that each of the complex output time series is an analytic signal.

To reduce anomalies in the $S$-transform output at the beginning and the end of the output time series, we used a Hanning window over the initial and final $100 \mathrm{~ms}$ of the input time series.
The output of the transform for each stimuli and electrode site was calculated by averaging the individual trials containing the timefrequency energy distributions. To quantify $S$-transform magnitudes, an ROI was identified by specifying the band of frequencies and the time interval contained in the rectangular ROI. The timefrequency points saved from each $S$ transformation are from 100 ms before to $900 \mathrm{~ms}$ after the onset of the stimulus, and from $1 \mathrm{~Hz}$ through $50 \mathrm{~Hz}$ at intervals of $0.5 \mathrm{~Hz}$. Energy is the square of the magnitude of the $S$-transform output in a time-frequency ROI. The $S$-transform output for a time-frequency ROI, for a specific EEG lead, is proportional to the input voltage of the lead over the time-frequency interval. The $S$-transform magnitude squared for a time-frequency interval is therefore proportional to volts squared. These analyses are similar to those previously described [57].

An $S$ transformation at time $t$ and frequency $f$ has real and imaginary parts

$$
S(t, f)=\operatorname{Re} S(t, f)+i \operatorname{Im} S(t, f)
$$

where $i$ is the square root of minus 1 . The cosine and sine of the phase angle at this time-frequency point are

$$
\begin{aligned}
& \cos \phi(t, f)=\operatorname{Re} S(t, f) /|S(t, f)| \\
& \sin \phi(t, f)=\operatorname{Im} S(t, f) /|S(t, f)|
\end{aligned}
$$

where the vertical bar pair indicates magnitude, here and below. The cosine and sine of phase angle are calculated from the $S$ transformation without having to calculate the phase angle.

PLI is a measure of synchrony of phase angle over trials, as a function of frequency and of time relative to the start of the stimulus for each trial. The range of PLI is from zero to 1.0, with high values at a time and frequency indicating little variation, among trials, of phase angle at that time and frequency. PLI is defined as

$$
P L I(t, f)=|\langle\cos \phi(t, f)+i \sin \phi(t, f)\rangle|
$$

where the angle bracket pair indicates mean value over eligible trials, here and below. Eligibility depends on the stimulus type and absence of significant artifact. This definition is based on cosine and sine of phase angles that are calculated from $S$ transformations without calculating phase angles. This definition is mathematically equivalent to the definition in Schack and Klimesch [58].

PDLI is a measure of constancy over trials of the difference in phase angle between two channels, as a function of frequency and of time relative to the start of the stimulus for each trial. The range of PDLI is from zero to 1.0, with high values at a time and frequency indicating little variation, among trials, of phase angle difference between channels of the pair, at that time and frequency. PDLI is defined for frequency $f$ at time $t$ as

$$
\begin{aligned}
\operatorname{PDLI}(t, f)= & \mid\left\langle\cos \left(\phi_{A}(t, f)-\phi_{B}(t, f)\right)\right\rangle \\
& +i\left\langle\sin \left(\phi_{A}(t, f)-\phi_{B}(t, f)\right)\right\rangle \mid
\end{aligned}
$$

where $\Phi_{\mathrm{A}}$ and $\Phi_{\mathrm{B}}$ are phase angles of channels A and B, respectively. This definition of PDLI is equivalent to a definition of PLV, phase lock value, in Brunner et al. [59]. By means of some standard trigonometric identities the equation above is equivalent to the following, which, as for PLI, does not require that the phase angles be calculated

$P D L I(t, f)=\left|\begin{array}{l}\left\langle\cos \phi_{A}(t, f) \cos \phi_{B}(t, f)+\sin \phi_{A}(t, f) \sin \phi_{B}(t, f)\right\rangle+ \\ i\left\langle\sin \phi_{A}(t, f) \cos \phi_{B}(t, f)-\cos \phi_{A}(t, f) \sin \phi_{B}(t, f)\right\rangle\end{array}\right|$ 
Rectangular ROIs were defined within the time-frequency analysis plane by specifying, for each ROI, a band of frequencies and a time interval relative to the stimulus onset time. Time 0 in these definitions is the onset of the stimulus. The ROI frequencies in both human and animal studies were as follows: delta $(1-4 \mathrm{~Hz})$, theta $(4-7 \mathrm{~Hz})$, alpha $(7-13 \mathrm{~Hz})$ and beta $(13-30 \mathrm{~Hz})$. The ROI time intervals were delta $(200-500 \mathrm{~ms})$, theta $(10-400 \mathrm{~ms})$, alpha (0-300 ms) and beta (0-300 ms). ROI time intervals were selected based on ERO energy in specific ERP component locations (N1, P3) in previous ERP studies [42]. Using mean values over trials, the maximum values were calculated for each ROI, for each electrode location or, for PDLI, for a pair of electrode locations (FZPZ) for energy, PLI amplitude and PDLI amplitude.

\section{Statistical Analyses}

The first set of analyses (IBM SPSS Statistics 20.0. Armonk, N.Y., USA) were aimed at determining whether the amount of: (1) energy, (2) degree of phase locking within electrode locations (PLI) and (3) degree of phase locking between electrode locations (PDLI) were different between the active and passive ERP paradigms used in the two sets of periadolescent human participants. Three multivariate analyses of variances (MANOVAs) were used to test between subject effects for energy, PLI and PDLI. Variables entered into the MANOVAs included the following: (1) group (active vs. passive task), (2) electrode location (FZ, CZ, PZ) for energy and PLI and FZ-PZ for PDLI, (3) tone (frequent and infrequent tones) and (4) the 4 time-frequency ROIs (delta, theta, alpha, beta). If significant main effects were found, repeated measures and interactions were explored using post hoc ANOVAs. To determine whether the age of the participants in the active task differed from those in the passive task a one-way ANOVA that compared the two groups was conducted. The second question focused on whether the periadolescent active task participants differed from the adult participants on energy, PDLI and PLI values. Three multivariate analyses of variance (MANOVAs) were used to test between subject age effects for energy, PLI and PDLI separately for the rats and the human participants. Variables entered into the MANOVAs were as follows: (1) group (periadolescent vs. adult), (2) electrode location (FZ, CZ, PZ) for energy and PLI and FZ-PZ for PDLI, (3) tone (frequent and infrequent tones) and (4) the 4 time-frequency ROIs (delta, theta, alpha, beta). If significant main effects were found, repeated measures and interactions were explored using post hoc ANOVAs. To determine whether the number of behavioral responses of the adults and periadolescent participants in the active task differed, a one-way ANOVA that compared the two groups was conducted. To reduce type 1 error, significance was set at $\mathrm{p}<0.01$.

\section{Results}

A total of 38 adult and 31 periadolescent human participants (all males) had valid electrophysiological data available for the current analyses. The adults had a mean $\pm \mathrm{SD}$ age of $20.53 \pm 2.08$ years (range $=18-25$ years) and $11.89 \pm 1.09$ years of education. The periadolescents had a mean \pm SD age of $12.0 \pm 1.5$ years (range $=10-14$ years)

Phase Locking Increases during

Adolescence
Table 1. Grand means for periadolescent humans by electroderecording locations

\begin{tabular}{llllll}
\hline & Grand mean & SE & F statistic & d.f. & p value \\
\hline Energy & & & & & \\
FZ & 54.43 & 6.77 & & & \\
CZ & 64.09 & 6.77 & 6.67 & 2,174 & 0.002 \\
PZ & 88.35 & 6.77 & & & \\
\hline PLI & & & & & \\
FZ & 0.44 & 0.01 & & & \\
CZ & 0.46 & 0.01 & 12.23 & 2,174 & $<0.001$ \\
PZ & 0.39 & 0.01 & & & \\
\hline
\end{tabular}

and $6.4 \pm 1.72$ years of education. Overall, 34 rats completed the protocol and had data available for analyses, though 2 rats had only one channel of electrophysiology data. The periadolescent rats were between PD33 and PD39 days old and had a mean \pm SE body weight of 142 $\pm 5.9 \mathrm{~g}$. The adult rats were between PD99 and PD117 days old and had a mean \pm SE body weight of $382 \pm 3.6 \mathrm{~g}$.

\section{ERO Responses to Frequent and Infrequent Tones}

in the Active and Passive Tasks in Periadolescent

\section{Humans}

One-way ANOVA revealed that there were no significant age differences between the periadolescent participants in the active task and those in the passive task. To address the first major research question, MANOVA was used to determine whether the values for energy, PLI or PDLI for the three electrode locations (FZ, CZ, PZ) differed between the infrequent and frequent tones, or differed between the active and passive task in the periadolescent humans. In the active task MANOVA revealed that no significant overall differences were found in measures of ERO energy for the effect of tone (frequent vs. infrequent tone) or group (active vs. passive task). However, there were significant overall effects of electrode location: $\mathrm{F}=6.7$, d.f. $=2,174$ and $\mathrm{p}<0.002$ (grand means: $\mathrm{FZ}=54.4 \pm 6.8, \mathrm{CZ}=64.1 \pm 6.8, \mathrm{PZ}=88.4 \pm 6.8$ ), with the $\mathrm{PZ}$ having higher energy than the $\mathrm{CZ}$ or $\mathrm{FZ}$, as seen in table 1. Evaluation of PLI values using MANOVA with repeated measures revealed a significant main effect of electrode location with higher PLI values in CZ than PZ: $\mathrm{F}=12.2$, d.f. $=2,174$ and $\mathrm{p}<0.001$ (grand means: $\mathrm{FZ}=$ $0.44 \pm 0.01, \mathrm{CZ}=0.46 \pm 0.01, \mathrm{PZ}=0.39 \pm 0.01)$. A significant main effect of tone was also found with increases in the PLI values obtained following the infrequent (target) tone compared to the frequent (nontarget) tone ( $\mathrm{F}=$ 


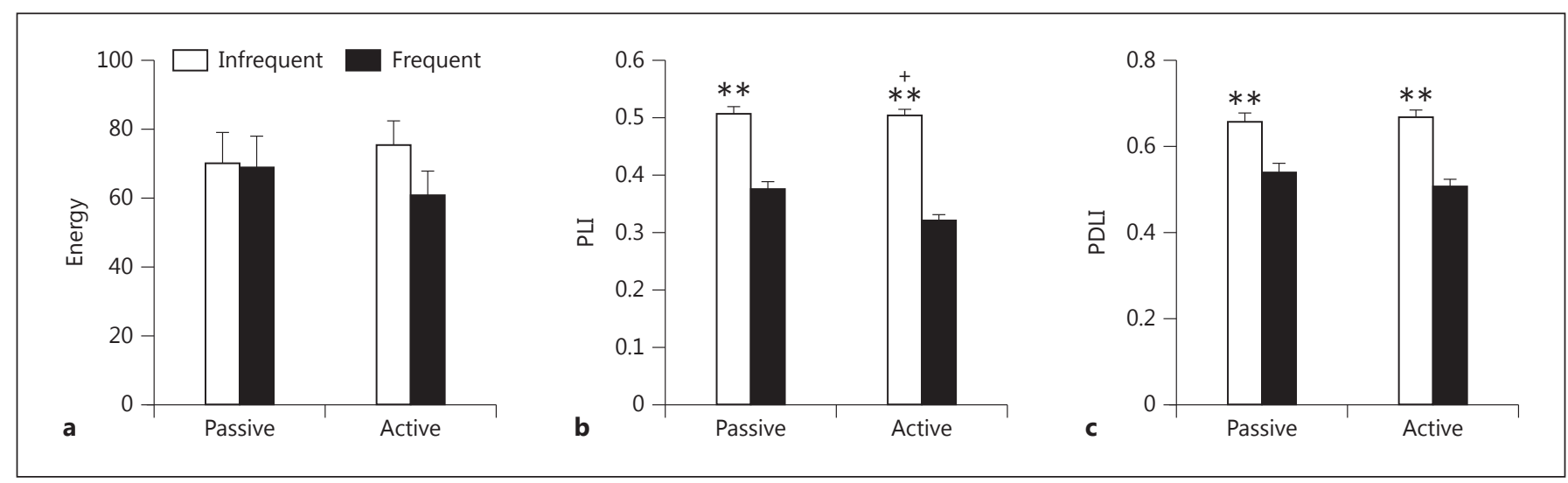

Fig. 1. Grand mean values for energy, PLI and PDLI of EROs for the passive and active task in periadolescents. a MANOVA revealed that the infrequent (target) tone, compared to the frequent (nontarget) tone, produced no significant differences in energy by tone or between passive and active task. b PLI was significantly increased following the infrequent tone compared to the frequent tone and was decreased in the active task. ${ }^{* *} \mathrm{p}<0.001 ;{ }^{+} \mathrm{p}<0.007$. c PDLI was also significantly increased following the infrequent tone but not different between the tasks. Error bars $=$ SEM.

Table 2. Means for frequent and infrequent tone of the active and passive task in periadolescent humans, with MANOVA

\begin{tabular}{llllrrr}
\hline Tone & $\begin{array}{l}\text { Passive, } \\
\text { mean } \pm \text { SE }\end{array}$ & $\begin{array}{l}\text { Active, } \\
\text { mean } \pm \text { SE }\end{array}$ & MANOVA & F statistic & d.f. & p value \\
\hline $\begin{array}{l}\text { Energy } \\
\text { Frequent }\end{array}$ & $69.05 \pm 8.65$ & $61.01 \pm 6.88$ & task & 0.03 & 1,174 & 0.862 \\
Infrequent & $70.22 \pm 8.65$ & $75.54 \pm 6.88$ & tone & 1.01 & 1,174 & 0.317 \\
\hline$P L I$ & & & & & & \\
Frequent & $0.38 \pm 0.01$ & $0.32 \pm 0.01$ & task & 7.44 & 1,174 & 0.007 \\
Infrequent & $0.51 \pm 0.01$ & $0.51 \pm 0.01$ & tone & 208.56 & 1,174 & $<0.001$ \\
\hline $\begin{array}{l}\text { PDLI } \\
\text { Frequent }\end{array}$ & & & & & & \\
Infrequent & $0.54 \pm 0.02$ & $0.51 \pm 0.02$ & task & 0.34 & 1,58 & 0.560 \\
\hline & $0.66 \pm 0.02$ & $0.67 \pm 0.02$ & tone & 56.70 & 1,58 & $<0.001$ \\
\hline
\end{tabular}

208.6, d.f. $=1,174, \mathrm{p}<0.001)$, as seen in table 2. Significant main effects of group (active vs. passive task) were also seen $(\mathrm{F}=7.4$, d.f. $=1,174, \mathrm{p}<0.007)$; these results are presented in figure $1 \mathrm{~b}$. The infrequent (target) tones had the same amplitude in the active versus the passive task but the frequent tone had lower PLI values in the active task.

A highly significant main effect of tone was found in PDLI between FZ and PZ ( $F=56.7$, d.f. $=1,58, \mathrm{p}<0.001)$, as also seen in figure $1 \mathrm{c}$. PDLI was found to be significantly higher following the infrequent (target) tone compared to the frequent (nontarget) tone. There were no significant main effects of PDLI as a function of group (active vs. passive task).

\section{Developmental Differences in EROs in Humans}

The second major research question concerned whether adults differed from periadolescents in ERO responses to auditory stimuli with an active task. A comparison of the number of behavioral responses given in the active task revealed that there were no significant differences between adults and periadolescents. The mean number of responses for the adults was $25.3 \pm 0.2$ and for the periadolescents the number was $26.5 \pm 0.6$ out of a total possible 25 responses. An evaluation of energy values in the human participants using MANOVA revealed a main effect of group (periadolescents vs. adults: $F=89.6$, d.f. $=1$, $330, \mathrm{p}<0.001$ ) and a main effect of tone (frequent vs. infrequent target: $\mathrm{F}=7.32$, d.f. $=1,330, \mathrm{p}<0.007)$. The in- 
Fig. 2. Significant mean values for energy of EROs following the infrequent (target) tone for periadolescents and adults in the delta $(1-4 \mathrm{~Hz}, 200-500 \mathrm{~ms})$, theta $(4-7 \mathrm{~Hz}$, 10-400 ms), alpha $(7-13 \mathrm{~Hz}, 0-300 \mathrm{~ms})$ and beta $(13-30 \mathrm{~Hz}, 0-300 \mathrm{~ms})$ time-frequency ranges for the 3 electrode locations (FZ, CZ, PZ) in humans (a; periadolescent: $\mathrm{n}=19$, adult: $\mathrm{n}=38$ ) and in rats (b; periadolescent: $n=15$, adult: $n=19$ ). Energy in periadolescents, compared to adults, is significantly higher across most frequency bands and electrode sites in humans and in rats. ${ }^{*} \mathrm{p}<0.01,{ }^{* *} \mathrm{p}<0.001$. Error bars $=$ SEM.
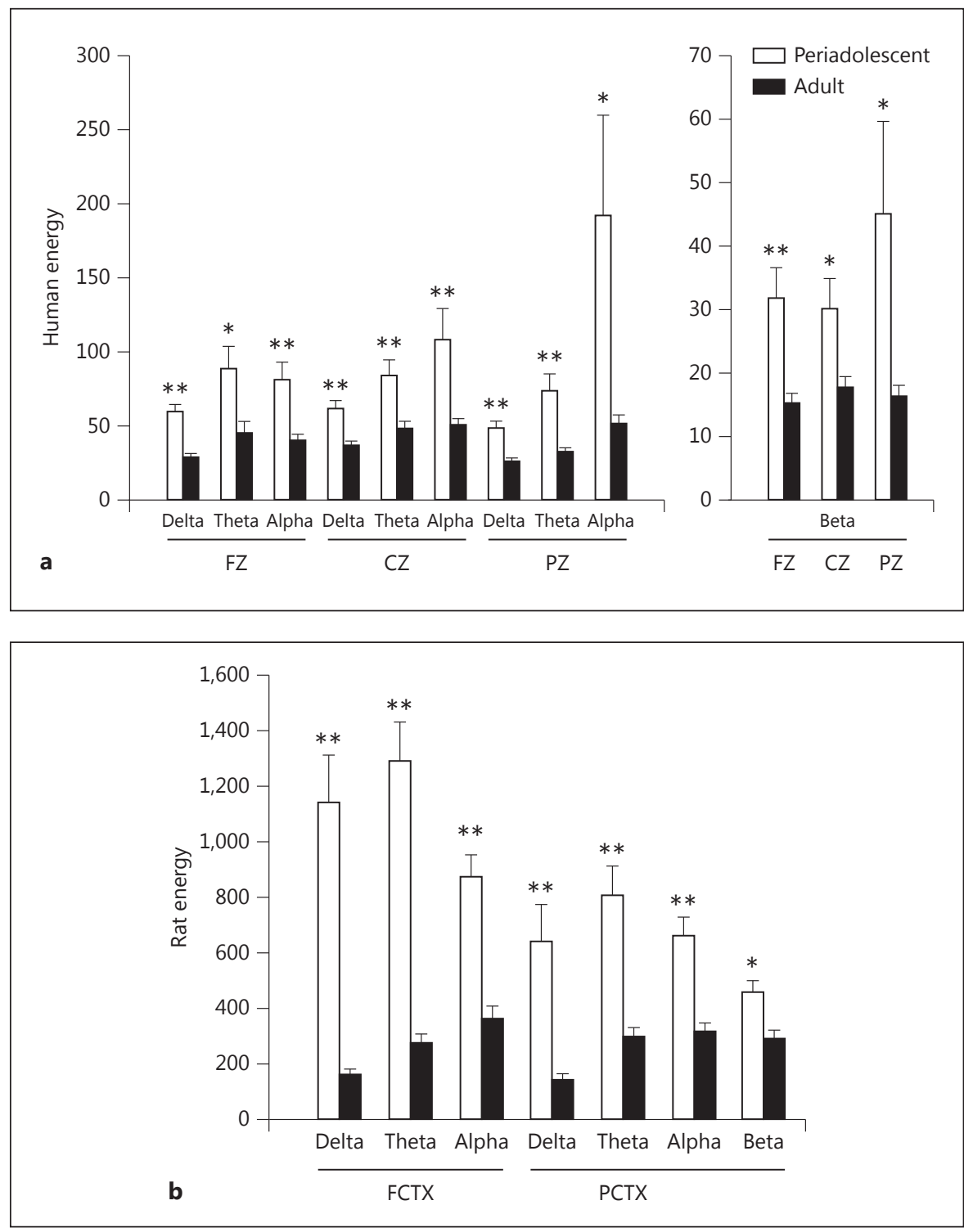

frequent (target) tone had a significantly higher overall energy $(54.89 \pm 2.8)$ than the frequent tone $(44.19 \pm 2.8)$. Grand means revealed that periadolescents had significantly higher energy $(68.28 \pm 3.2)$ than adults $(30.8 \pm 2.3)$. ANOVA identified that for the frequently presented tone, periadolescents had significantly higher energy than adults in all electrode locations for all time-frequency ROIs except for theta activity in FZ (F value range $=7.6-$ 74.7).

As seen in figure 2a, the ANOVA revealed that periadolescents also had significantly higher energy values than adults to the infrequent (target) tone in the delta $(\mathrm{F}=43.1$, d.f. $=1,56, \mathrm{p}<0.001)$, theta $(\mathrm{F}=8.4$, d.f. $=1$,
56, $\mathrm{p}=0.005)$, alpha $(\mathrm{F}=18.3$, d.f. $=1,56, \mathrm{p}<0.001)$ and beta $(\mathrm{F}=17.7$, d.f. $=1,56, \mathrm{p}<0.001)$ frequency ranges in $\mathrm{FZ}$ and in the delta $(\mathrm{F}=23.4$, d.f. $=1,56, \mathrm{p}<0.001)$, theta $(\mathrm{F}=14.6$, d.f. $=1,56, \mathrm{p}<0.001)$, alpha $(\mathrm{F}=13.9$, d.f. $=1$, $56, \mathrm{p}<0.001)$ and beta $(\mathrm{F}=9.7$, d.f. $=1,56, \mathrm{p}=0.003)$ frequencies in the CZ. Significant reductions in energy were also seen in the adults compared to the periadolescents to the infrequent (target) tone at parietal sites (PZ) in the delta $(\mathrm{F}=30.5$, d.f. $=1,56, \mathrm{p}<0.001)$, theta $(\mathrm{F}=$ 23.5 , d.f. $=1,56, \mathrm{p}<0.001)$, alpha $(\mathrm{F}=8.6$, d.f. $=1,56$, $\mathrm{p}=0.005)$ and beta $(\mathrm{F}=7.6$, d.f. $=1,56, \mathrm{p}=0.008)$ frequency ranges, as seen in table 3 . Grand averages of the energy values for the entire group of participants $(n=57)$ 
Table 3. Energy results for infrequent tone by age in both humans (active task) and rats

\begin{tabular}{|c|c|c|c|c|c|c|c|}
\hline & \multicolumn{2}{|c|}{ Adults } & \multicolumn{2}{|c|}{ Periadolescents } & \multirow[t]{2}{*}{ F statistic } & \multirow[t]{2}{*}{ d.f. } & \multirow[t]{2}{*}{$\mathrm{p}$ value } \\
\hline & $\mathrm{n}$ & mean $\pm \mathrm{SE}$ & $\mathrm{n}$ & mean $\pm \mathrm{SE}$ & & & \\
\hline \multicolumn{8}{|l|}{ Humans } \\
\hline \multicolumn{8}{|l|}{ FZ } \\
\hline Delta & 38 & $29.01 \pm 2.27$ & 19 & $59.61 \pm 4.80$ & 43.07 & 1,56 & $<0.001$ \\
\hline Theta & 38 & $45.23 \pm 7.53$ & 19 & $88.75 \pm 15.00$ & 8.43 & 1,56 & 0.005 \\
\hline Alpha & 38 & $40.42 \pm 3.77$ & 19 & $81.36 \pm 11.34$ & 18.26 & 1,56 & $<0.001$ \\
\hline Beta & 38 & $15.23 \pm 1.50$ & 19 & $31.77 \pm 4.71$ & 17.73 & 1,56 & $<0.001$ \\
\hline \multicolumn{8}{|l|}{$\mathrm{CZ}$} \\
\hline Delta & 38 & $37.00 \pm 2.59$ & 19 & $62.01 \pm 5.19$ & 23.38 & 1,56 & $<0.001$ \\
\hline Theta & 38 & $48.39 \pm 4.26$ & 19 & $84.30 \pm 10.25$ & 14.64 & 1,56 & $<0.001$ \\
\hline Alpha & 38 & $50.67 \pm 4.06$ & 19 & $108.50 \pm 20.52$ & 13.94 & 1,56 & $<0.001$ \\
\hline Beta & 38 & $17.67 \pm 1.62$ & 19 & $30.13 \pm 4.67$ & 9.68 & 1,56 & 0.003 \\
\hline \multicolumn{8}{|l|}{$\mathrm{PZ}$} \\
\hline Delta & 38 & $26.34 \pm 2.04$ & 19 & $48.83 \pm 4.10$ & 30.46 & 1,56 & $<0.001$ \\
\hline Theta & 38 & $32.67 \pm 2.41$ & 19 & $73.98 \pm 11.13$ & 23.53 & 1,56 & $<0.001$ \\
\hline Alpha & 38 & $52.02 \pm 5.29$ & 19 & $192.21 \pm 67.31$ & 8.62 & 1,56 & 0.005 \\
\hline Beta & 38 & $16.33 \pm 1.62$ & 19 & $45.04 \pm 14.49$ & 7.61 & 1,56 & 0.008 \\
\hline \multicolumn{8}{|l|}{ Rats } \\
\hline \multicolumn{8}{|l|}{ FCTX } \\
\hline Delta & 19 & $163.39 \pm 18.01$ & 14 & $1,141.14 \pm 170.46$ & 44.24 & 1,32 & $<0.001$ \\
\hline Theta & 19 & $276.73 \pm 31.54$ & 14 & $1,289.59 \pm 140.81$ & 64.92 & 1,32 & $<0.001$ \\
\hline Alpha & 19 & $363.79 \pm 45.35$ & 14 & $875.34 \pm 77.35$ & 36.49 & 1,32 & $<0.001$ \\
\hline Beta & 19 & $408.99 \pm 50.62$ & 14 & $593.89 \pm 63.04$ & 5.34 & 1,32 & 0.028 \\
\hline \multicolumn{8}{|l|}{ PCTX } \\
\hline Delta & 18 & $144.15 \pm 19.96$ & 15 & $642.80 \pm 131.31$ & 16.85 & 1,32 & $<0.001$ \\
\hline Theta & 18 & $299.55 \pm 31.59$ & 15 & $809.12 \pm 103.86$ & 25.62 & 1,32 & $<0.001$ \\
\hline Alpha & 18 & $319.02 \pm 28.63$ & 15 & $663.10 \pm 65.33$ & 26.18 & 1,32 & $<0.001$ \\
\hline Beta & 18 & $292.85 \pm 28.02$ & 15 & $459.83 \pm 40.98$ & 11.93 & 1,32 & 0.002 \\
\hline
\end{tabular}

given the active task, to the infrequent (target) tone for the periadolescents and adults, are presented in figure 3.

An evaluation of PLI values in the human participants using MANOVA revealed a main effect of group (periadolescents vs. adults: $\mathrm{F}=88.1$, d.f. $=1,330, \mathrm{p}<0.001$ ) and a main effect of tone (frequent vs. infrequent target: $\mathrm{F}=364.6$, d.f. $=1,330, \mathrm{p}<0.001)$ and of electrode location (10.6, d.f. $=2,330, \mathrm{p}<0.001)$. The infrequent (target) tone had a significantly higher grand mean PLI value $(0.55 \pm 0.007)$ than the frequent tone $(0.37 \pm 0.007)$. Grand means also revealed that periadolescents had significantly lower PLI values (0.41) than adults (0.5). ANOVA identified that for the frequently presented tone, periadolescents had significantly lower PLI than adults for delta and theta activity for all electrode locations ( $F$ value range $=8.6-42.8$ )

Figure 4 a gives the mean $( \pm$ SE) values for the PLI for each frequency range for the three electrode locations for the periadolescents and adults, for the infrequent (target) tone in the human participants. Repeated measures ANOVA revealed that adults had significantly higher PLI levels than periadolescents to the infrequent (target) tone in the delta $(\mathrm{F}=6.7$, d.f. $=1,56, \mathrm{p}=0.01)$ and theta $(\mathrm{F}=$ 8.4, d.f. $=1,56, \mathrm{p}=0.005)$ frequencies in $\mathrm{FZ}$ and in the delta $(\mathrm{F}=18.9$, d.f. $=1,56, \mathrm{p}=0.001)$ and theta $(\mathrm{F}=8.1$, d.f. $=1,56, p<0.006)$ frequency ranges in $\mathrm{CZ}$, as seen in table 4. Significant increases in PLI were also seen in the adults compared to the periadolescents at parietal sites $(\mathrm{PZ})$ in the delta $(\mathrm{F}=22.2$, d.f. $=1,56, \mathrm{p}<0.001)$ and theta $(\mathrm{F}=9.2$, d.f. $=1,56, \mathrm{p}<0.004)$ frequency ranges for the infrequent (target) tone. Grand averages of PLI values for the infrequent (target) tone for periadolescents and adults in the active task are seen in figure 5.

An evaluation of PDLI values in the human participants for the electrode pair FZ and PZ using MANOVA revealed a main effect of group (periadolescents vs. adults: $\mathrm{F}=72.6$, d.f. $=1,110, \mathrm{p}<0.001)$ and a main effect of tone (frequent vs. infrequent target: $\mathrm{F}=132.3$, d.f. $=1,110$, 


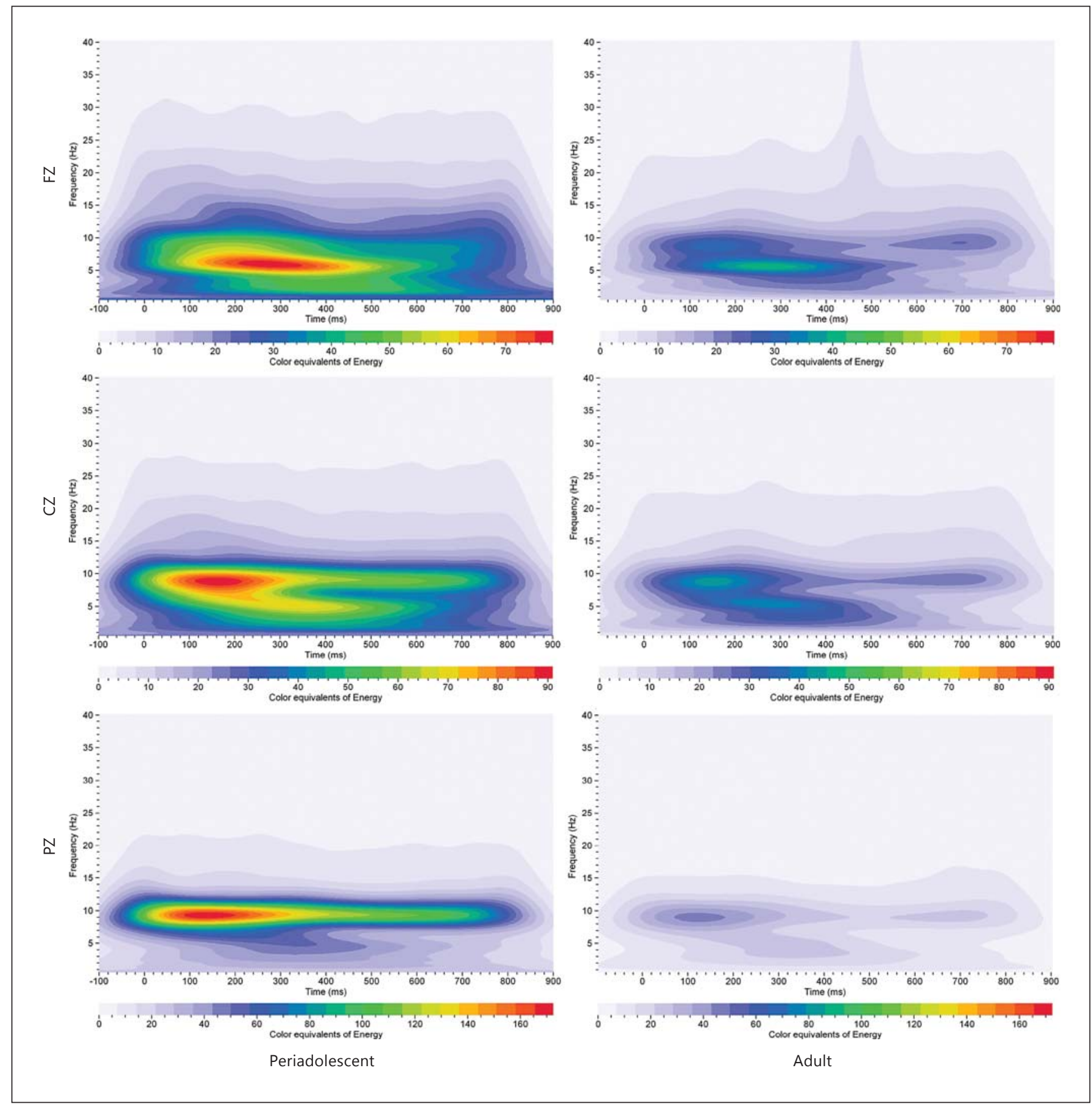

Fig. 3. Grand averages of energy for EROs in humans given the active task (periadolescent: $\mathrm{n}=19$, adult: $\mathrm{n}=38$ ). Each graph depicts a time-frequency representation of energy values in periadolescents and adults following the infrequent (target) tone in the 3 electrode locations (FZ, CZ, PZ). In each graph, frequency (in hertz) is presented on the $y$-axis and time ROIs on the $\mathrm{x}$-axis (in milliseconds). Energy is presented as color equivalents as indicated on the bar at the bottom of each graph. Periadolescents show overall higher energy across the time frequencies and in all electrode sites compared to adults. 

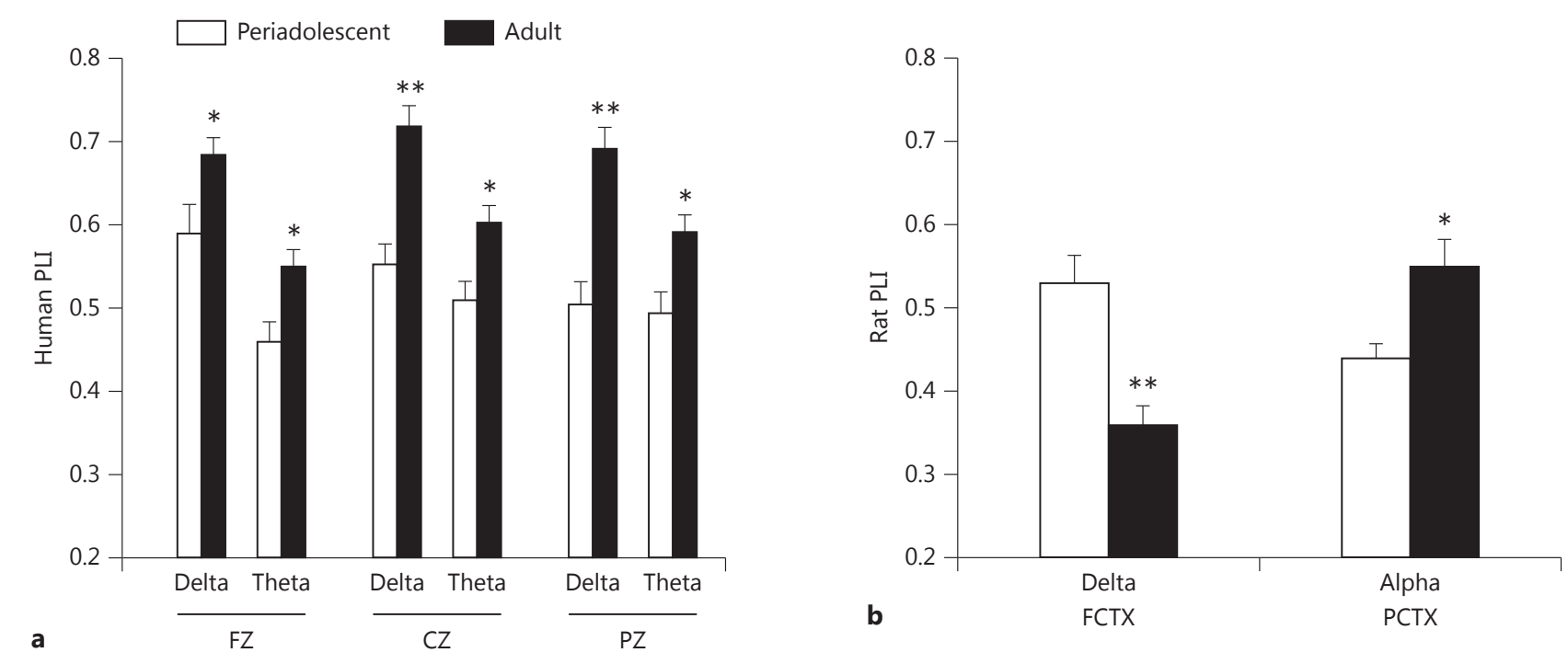

Fig. 4. Significant mean values for the PLI of EROs following the infrequent (target) tone for periadolescents and adults for delta (1-4 Hz, 200-500 ms), theta (4-7 Hz, 10-400 ms) and alpha (7-13 $\mathrm{Hz}, 0-300 \mathrm{~ms}$ ) time-frequency ranges. a Human adults (periadolescent: $\mathrm{n}=19$, adult: $\mathrm{n}=38$ ) showed significantly higher PLI in the delta and theta time frequencies across all 3 electrode locations

$\mathrm{p}<0.001$ ). The infrequent (target) tone had a significantly higher grand mean PDLI value $(0.73 \pm 0.01)$ than the frequent tone $(0.57 \pm 0.01)$. Grand means also revealed that periadolescents had significantly lower PDLI values (0.59) than adults (0.71). ANOVA identified that for the frequently presented tone, periadolescents had significantly lower PDLI than adults for all time-frequency ROIs ( $F$ value range $=7.3-43.0$ ).

The PDLI for the electrode pair FZ and PZ for the infrequent (target) tone for human adults and periadolescents is shown in figure 6a. Repeated measures ANOVA revealed that periadolescents had significantly lower PDLI levels than adults to the infrequent (target) tone in the delta $(\mathrm{F}=26.4$, d.f. $=1,56, \mathrm{p}<0.001)$, theta $(\mathrm{F}=41.2$, d.f. $=1,56, \mathrm{p}<0.001)$, alpha $(\mathrm{F}=13.3$, d.f. $=1,56, \mathrm{p}=$ $0.001)$ and beta $(\mathrm{F}=9.4$, d.f. $=1,56, \mathrm{p}=0.003)$ frequency ranges, as seen in table 5 .

\section{Developmental Differences in EROs in Rats}

The second major research question also concerned whether adults differed from periadolescents in ERO responses to auditory stimuli in rats. An evaluation of energy values in the rats using MANOVA revealed a main effect of group (periadolescents vs. adults: $\mathrm{F}=152.1$, compared to periadolescents. b Adult rats (periadolescent: $\mathrm{n}=15$, adult: $n=19$ ) showed a significant decrease in the delta time frequency in the FCTX and an increase in alpha time frequencies in the PCTX compared to periadolescents. ${ }^{*} \mathrm{p}<0.01,{ }^{* *} \mathrm{p}<0.001$. Error bars $=$ SEM.

d.f. $=1,124, \mathrm{p}<0.001$ ), a main effect of tone (frequent vs. infrequent: $\mathrm{F}=8.7$, d.f. $=1,124, \mathrm{p}=0.004)$ and a main effect of electrode location ( $\mathrm{F}=12.4$, d.f. $=1,124, \mathrm{p}=$ $0.001)$. The infrequent tone had a significantly higher overall energy $(546.5 \pm 27.4)$ than the frequent tone (431.9 \pm 27.4 ). Grand means revealed that periadolescents had significantly higher energy $(728.1 \pm 29.0)$ than adults $(250.2 \pm 25.7)$. ANOVA identified that for the frequently presented tone, periadolescents had significantly higher energy than adults in all electrode locations for all timefrequency ROIs (F value range $=10.2-57.1$ ).

Age produced similar results on energy values collected following the infrequent tone in the rats. Grand averages of the energy values for the group of rats with complete data $(n=31)$ for the periadolescent and the adult rats for the infrequent tone are presented in figure 7. Repeated measures ANOVA revealed that periadolescents had significantly higher energy values than adults to the infrequent (target) tone in the delta $(\mathrm{F}=44.2$, d.f. $=1,32$, $\mathrm{p}<0.001)$, theta $(\mathrm{F}=64.9$, d.f. $=1,32, \mathrm{p}<0.001)$, and alpha $(\mathrm{F}=36.5$, d.f. $=1,32, \mathrm{p}<0.001)$ frequency ranges in the rat frontal cortex (FCTX) and in the rat parietal cortex (PCTX) in the delta $(\mathrm{F}=16.9$, d.f. $=1,32, \mathrm{p}<0.001)$, theta $(\mathrm{F}=25.6$, d.f. $=1,32, \mathrm{p}<0.001)$, alpha $(\mathrm{F}=26.2$, d.f. $=$ 
Table 4. PLI results for infrequent tone by age in both humans (active task) and rats

\begin{tabular}{|c|c|c|c|c|c|c|c|}
\hline & \multicolumn{2}{|c|}{ Adults } & \multicolumn{2}{|c|}{ Periadolescents } & \multirow[t]{2}{*}{ F statistic } & \multirow[t]{2}{*}{ d.f. } & \multirow[t]{2}{*}{$\mathrm{p}$ value } \\
\hline & $\mathrm{n}$ & mean $\pm \mathrm{SE}$ & $\mathrm{n}$ & mean $\pm \mathrm{SE}$ & & & \\
\hline \multicolumn{8}{|l|}{ Humans } \\
\hline \multicolumn{8}{|l|}{$\mathrm{FZ}$} \\
\hline Delta & 38 & $0.68 \pm 0.02$ & 19 & $0.59 \pm 0.03$ & 6.72 & 1,56 & 0.012 \\
\hline Theta & 38 & $0.55 \pm 0.02$ & 19 & $0.46 \pm 0.02$ & 8.44 & 1,56 & 0.005 \\
\hline Alpha & 38 & $0.54 \pm 0.02$ & 19 & $0.49 \pm 0.03$ & 3.03 & 1,56 & 0.087 \\
\hline Beta & 38 & $0.55 \pm 0.02$ & 19 & $0.53 \pm 0.02$ & 1.19 & 1,56 & 0.281 \\
\hline \multicolumn{8}{|l|}{$\mathrm{CZ}$} \\
\hline Delta & 38 & $0.72 \pm 0.02$ & 19 & $0.55 \pm 0.02$ & 18.86 & 1,56 & $<0.001$ \\
\hline Theta & 38 & $0.60 \pm 0.02$ & 19 & $0.51 \pm 0.02$ & 8.06 & 1,56 & 0.006 \\
\hline Alpha & 38 & $0.59 \pm 0.02$ & 19 & $0.53 \pm 0.02$ & 3.14 & 1,56 & 0.082 \\
\hline Beta & 38 & $0.55 \pm 0.02$ & 19 & $0.49 \pm 0.03$ & 3.28 & 1,56 & 0.076 \\
\hline \multicolumn{8}{|l|}{$\mathrm{PZ}$} \\
\hline Delta & 38 & $0.69 \pm 0.02$ & 19 & $0.50 \pm 0.03$ & 22.18 & 1,56 & $<0.001$ \\
\hline Theta & 38 & $0.59 \pm 0.02$ & 19 & $0.49 \pm 0.03$ & 9.18 & 1,56 & 0.004 \\
\hline Alpha & 38 & $0.53 \pm 0.02$ & 19 & $0.45 \pm 0.03$ & 4.07 & 1,56 & 0.048 \\
\hline Beta & 38 & $0.49 \pm 0.02$ & 19 & $0.47 \pm 0.02$ & 0.89 & 1,56 & 0.349 \\
\hline \multicolumn{8}{|l|}{ Rats } \\
\hline \multicolumn{8}{|l|}{ FCTX } \\
\hline Delta & 19 & $0.36 \pm 0.02$ & 14 & $0.53 \pm 0.03$ & 19.27 & 1,32 & $<0.001$ \\
\hline Theta & 19 & $0.49 \pm 0.03$ & 14 & $0.56 \pm 0.04$ & 1.85 & 1,32 & 0.183 \\
\hline Alpha & 19 & $0.68 \pm 0.03$ & 14 & $0.61 \pm 0.03$ & 2.21 & 1,32 & 0.147 \\
\hline Beta & 19 & $0.76 \pm 0.03$ & 14 & $0.68 \pm 0.03$ & 4.26 & 1,32 & 0.048 \\
\hline \multicolumn{8}{|l|}{ PCTX } \\
\hline Delta & 18 & $0.41 \pm 0.02$ & 15 & $0.43 \pm 0.02$ & 0.74 & 1,32 & 0.397 \\
\hline Theta & 18 & $0.43 \pm 0.02$ & 15 & $0.39 \pm 0.02$ & 2.19 & 1,32 & 0.149 \\
\hline Alpha & 18 & $0.55 \pm 0.03$ & 15 & $0.44 \pm 0.02$ & 8.67 & 1,32 & 0.006 \\
\hline Beta & 18 & $0.67 \pm 0.03$ & 15 & $0.63 \pm 0.03$ & 0.61 & 1,32 & 0.443 \\
\hline
\end{tabular}

$1,32, \mathrm{p}<0.001)$ and beta $(\mathrm{F}=11.9$, d.f. $=1,32, \mathrm{p}=0.002)$ frequencies as seen in figure $2 \mathrm{~b}$ and table 3 .

An evaluation of PLI values in the rats using MANOVA revealed a main effect of tone (frequent vs. infrequent: $\mathrm{F}=$ 160.7, d.f. $=1,124, \mathrm{p}<0.001)$ and a main effect of electrode location $(\mathrm{F}=25.9$, d.f. $=1,124, \mathrm{p}<0.001)$. The infrequent tone had a significantly higher PLI value $(0.54 \pm 0.01)$ than the frequent tone $(0.34 \pm 0.01)$. Grand means revealed that FCTX had significantly higher PLI values $(0.48 \pm 0.01)$ than PCTX $(0.4 \pm 0.01)$. Exploratory repeated measures ANOVA revealed that periadolescent rats had significantly higher PLI levels than adult rats to the infrequent tone in the delta frequencies in FCTX $(\mathrm{F}=19.3$, d.f. $=1,32, \mathrm{p}<$ 0.001 ) and lower PLI values in the alpha frequencies in PCTX $(\mathrm{F}=8.7$, d.f. $=1,32, \mathrm{p}=0.006)$; data presented in figure $4 \mathrm{~b}$ and table 4 . Grand averages of the PLI values for periadolescent and adult rats are presented in figure 8 .

An evaluation of PDLI values in the rats for the electrode pair FCTX and PCTX using MANOVA revealed a main effect of group (periadolescents vs. adults: $\mathrm{F}=75.1$, d.f. $=1,60, p<0.001$ ) and a main effect of tone (frequent vs. infrequent: $\mathrm{F}=65.4$, d.f. $=1,60, \mathrm{p}<0.001)$. The infrequent tone had a significantly higher grand mean PDLI value $(0.71 \pm 0.01)$ than the frequent tone $(0.58 \pm 0.01)$. Grand means also revealed that periadolescents had significantly lower PDLI values (0.57) than adults (0.71). ANOVA identified that for the frequently presented tone, periadolescents had significantly lower PDLI than adults for all time-frequency ROIs except delta (F value range = 18.8-52.4). The PDLI for the electrode pair FCTX and PCTX for the infrequent tone in adult and periadolescent rats is shown in figure $6 \mathrm{~b}$ and table 5 . Repeated measures ANOVA revealed that periadolescent rats had significantly lower PDLI levels than adults to the infrequent tone in the theta $(\mathrm{F}=28.9$, d.f. $=1,31, \mathrm{p}<0.001)$, alpha $(\mathrm{F}=45.3$, d.f. $=1,31, \mathrm{p}<0.001)$ and beta $(\mathrm{F}=11.1$, d.f. $=$ $1,31, \mathrm{p}=0.002)$ frequency ranges. 


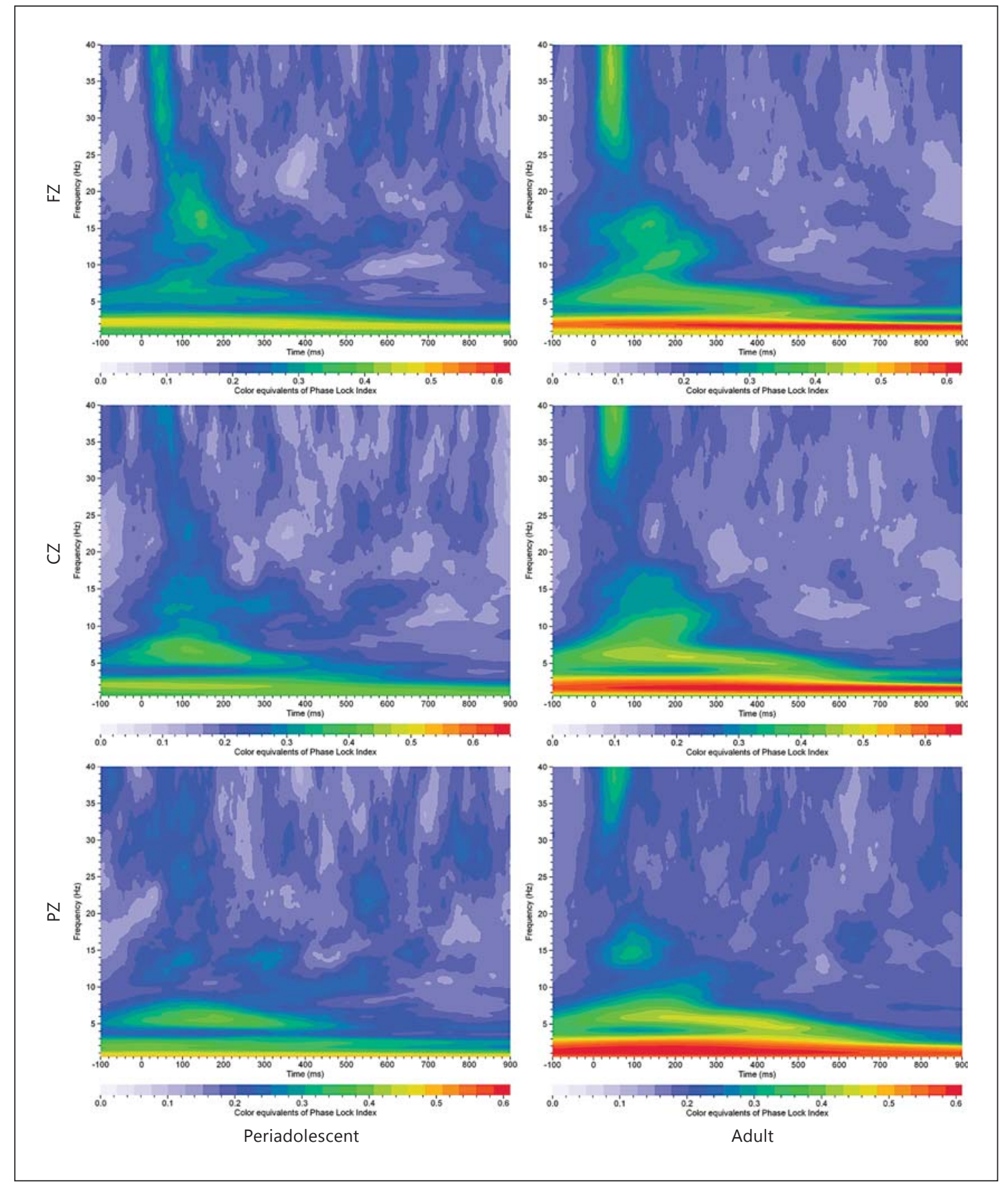

Fig. 5. Grand averages of PLI for EROs in humans given the active task (periadolescent: $n=19$, adult: $n=38$ ). Each graph depicts a time-frequency representation of phase angle synchrony values in periadolescents and adults following the infrequent (target) tone in the 3 electrode locations (FZ, CZ, PZ). In each graph frequency (in hertz) is presented on the $\mathrm{y}$-axis and time ROIs on the $\mathrm{x}$-axis (in milliseconds). PLI is presented as color equivalents as indicated on the bar at the bottom of each graph. 


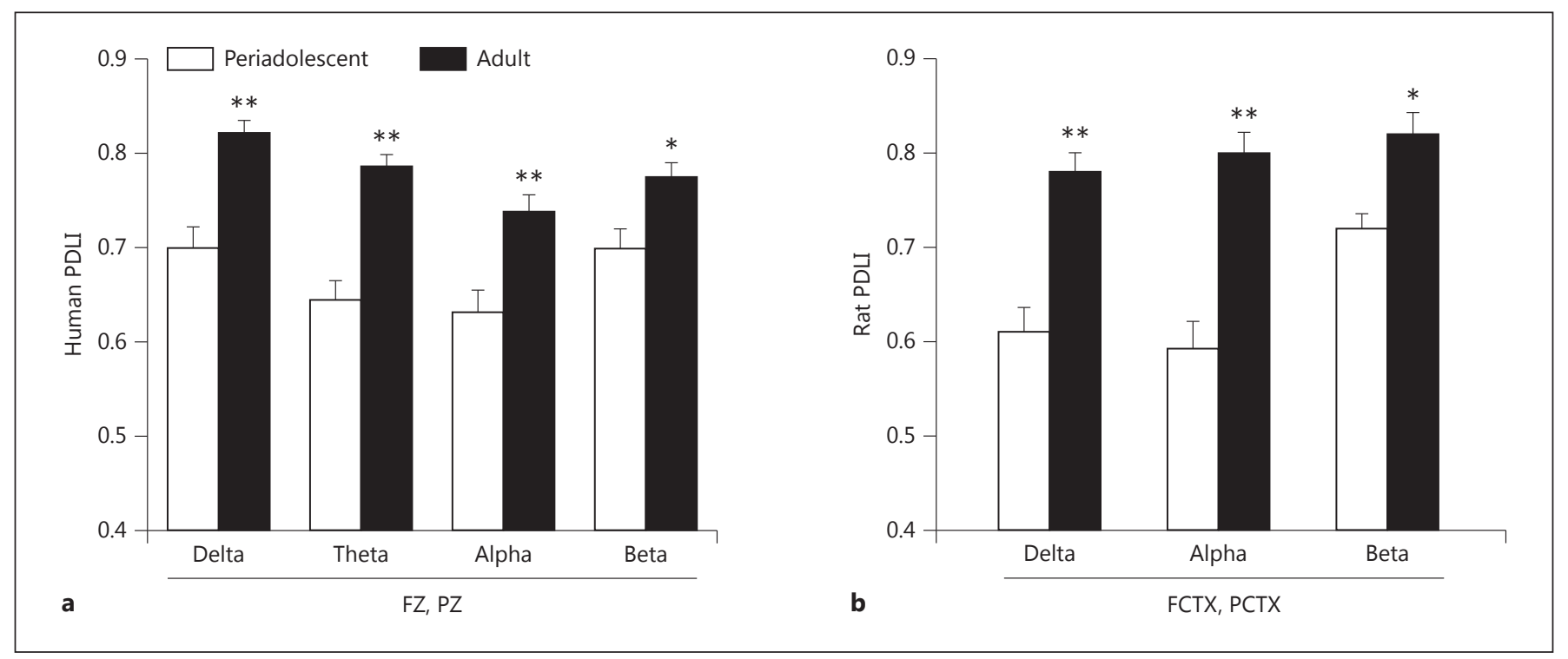

Fig. 6. Significant mean values for the PDLI of EROs following the infrequent (target) tone for periadolescents and adults in the delta (1-4 Hz, 200-500 ms), theta (4-7 Hz, 10-400 ms), alpha (7-13 Hz, $0-300 \mathrm{~ms})$ and beta $(13-30 \mathrm{~Hz}, 0-300 \mathrm{~ms})$ time-frequency ranges. Phase differences were calculated between FZ and PZ for the human study and between FCTX and PCTX in the rat study. a Hu- man adults showed significantly increased PDLI across all frequency bands compared to periadolescents. b Adult rats (periadolescent: $\mathrm{n}=14$, adult: $\mathrm{n}=18$ ) also had significant increases in PDLI in the theta, alpha and beta time frequencies. ${ }^{*} \mathrm{p}<0.01,{ }^{* *} \mathrm{p}<$ 0.001. Error bars $=$ SEM.

Table 5. PDLI results for infrequent tone by age in both humans (active task, FZ-PZ) and rats (FCTX-PCTX)

\begin{tabular}{|c|c|c|c|c|c|c|c|}
\hline & \multicolumn{2}{|c|}{ Adults } & \multicolumn{2}{|c|}{ Periadolescents } & \multirow[t]{2}{*}{ F statistic } & \multirow[t]{2}{*}{ d.f. } & \multirow[t]{2}{*}{$\mathrm{p}$ value } \\
\hline & $\mathrm{n}$ & mean $\pm \mathrm{SE}$ & $\mathrm{n}$ & mean $\pm \mathrm{SE}$ & & & \\
\hline \multicolumn{8}{|c|}{ Humans } \\
\hline Delta & 38 & $0.82 \pm 0.01$ & 19 & $0.70 \pm 0.02$ & 26.42 & 1,56 & $<0.001$ \\
\hline Theta & 38 & $0.79 \pm 0.01$ & 19 & $0.64 \pm 0.02$ & 41.15 & 1,56 & $<0.001$ \\
\hline Alpha & 38 & $0.74 \pm 0.02$ & 19 & $0.63 \pm 0.02$ & 13.31 & 1,56 & 0.001 \\
\hline Beta & 38 & $0.78 \pm 0.01$ & 19 & $0.70 \pm 0.02$ & 9.42 & 1,56 & 0.003 \\
\hline \multicolumn{8}{|l|}{ Rats } \\
\hline Delta & 18 & $0.70 \pm 0.02$ & 14 & $0.63 \pm 0.02$ & 5.34 & 1,31 & 0.028 \\
\hline Theta & 18 & $0.78 \pm 0.02$ & 14 & $0.61 \pm 0.03$ & 28.94 & 1,31 & $<0.001$ \\
\hline Alpha & 18 & $0.80 \pm 0.02$ & 14 & $0.60 \pm 0.02$ & 45.35 & 1,31 & $<0.001$ \\
\hline Beta & 18 & $0.82 \pm 0.02$ & 14 & $0.72 \pm 0.02$ & 11.08 & 1,31 & 0.002 \\
\hline
\end{tabular}

\section{Discussion}

Brain histochemical studies have shown that during early and mid-childhood there is a proliferation of synapses, particularly in cortical areas [60-62]. This process of synaptogenesis, depending on the species, may last for months or years and is then followed by a period of selec- tive elimination ('pruning'), during adolescence, which is partly experience dependent [63-66]. During this same period a chronological sequence of myelination of axons occurs with the prefrontal and association cortices being the last to develop [62]. It has been suggested that subcortical circuitry involving such structures as the ventral striatum, insula and extended amygdala, which are involved 


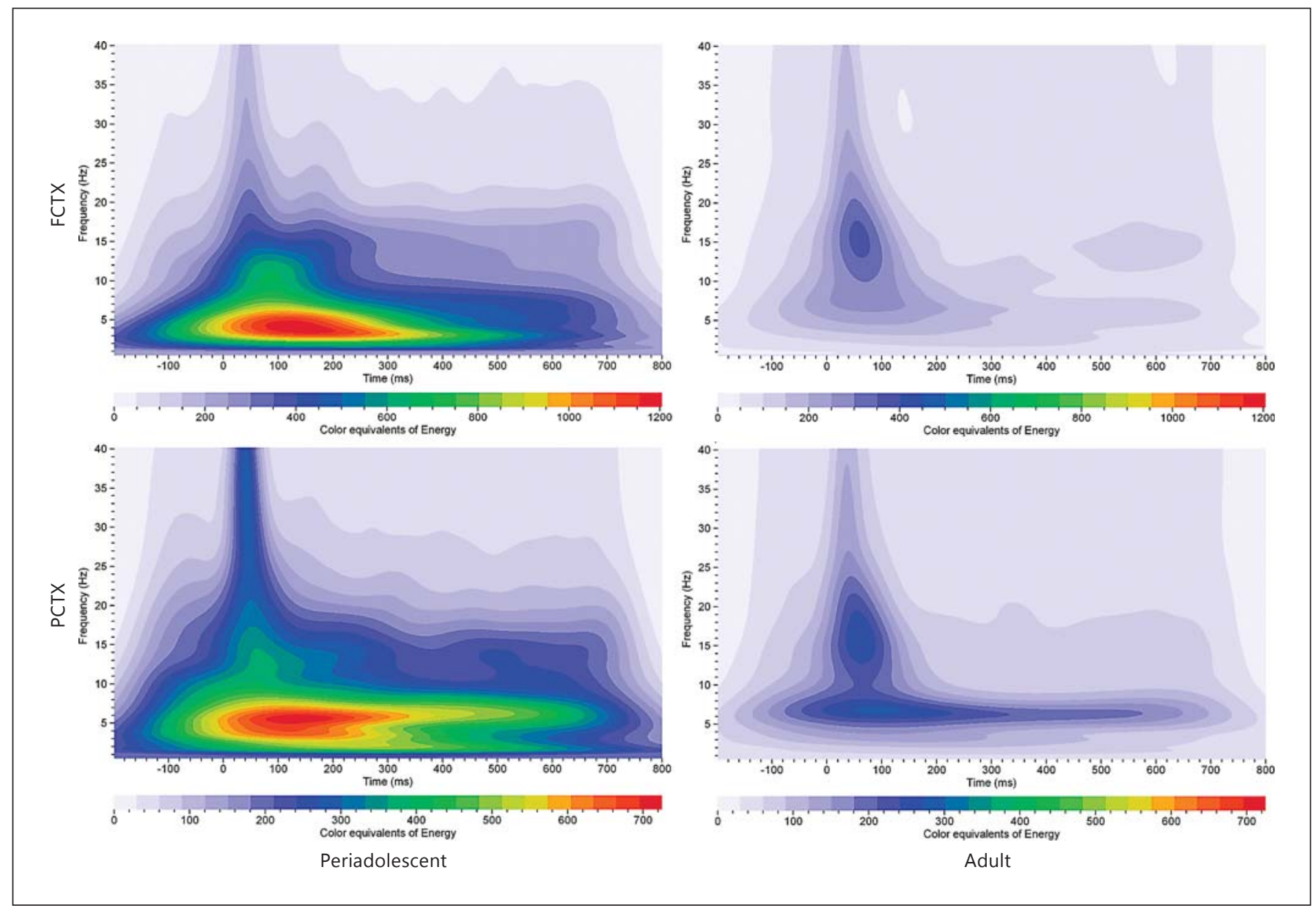

Fig. 7. Grand averages of energy for EROs in rats (periadolescent: $n=13$, adult: $n=18$ ). Each graph depicts a time-frequency representation of energy values in periadolescent and adult rats following the infrequent (target) tone in the 2 electrode locations (FCTX, PCTX). In each graph, frequency (in hertz) is presented on the $y$ -

in motivation and reward, may develop early in adolescence relative to frontal cortical circuits that subserve executive cognitive control functions, thus leading to the predisposition to behavioral disinhibition and risk taking often seen in adolescence [for review, see 67, 68].

Imaging techniques, in particular MRI and fMRI, have allowed for large quantitative cross-sectional and longitudinal studies of the trajectory of brain development over adolescence to be mapped [for review, see 69, 70]. These studies have added temporal detail to the histochemical studies and have demonstrated that cortical volume decreases across adolescence while white matter volume increases, particularly in the prefrontal cortex [71]. A different approach has been accomplished by studies utilizing graph theory analyses to evaluate patterns of axis and time ROIs on the $\mathrm{x}$-axis (in milliseconds). Energy is presented as color equivalents as indicated on the bar at the bottom of each graph. Periadolescent rats show greater energy across the time frequencies and in both electrode sites compared to adult rats.

low-frequency temporal correlations in fMRI signal to determine how network characteristics of brain-wide patterns may change from childhood to adulthood. These studies suggest that in childhood brain networks are more localized with the functional connectivity being more short range, whereas in adults the networks are spread out over larger areas with more long-range connections [72$75]$. While these structural studies provide important information on the trajectory of brain development they shed less light on how changes in cognitive functions are related to brain activity in specific neuronal networks, in real time, and how those functions might change over the life span [76].

Macroelectrophysiological recordings reflect the activity of large-scale neuronal assemblies and have the po- 


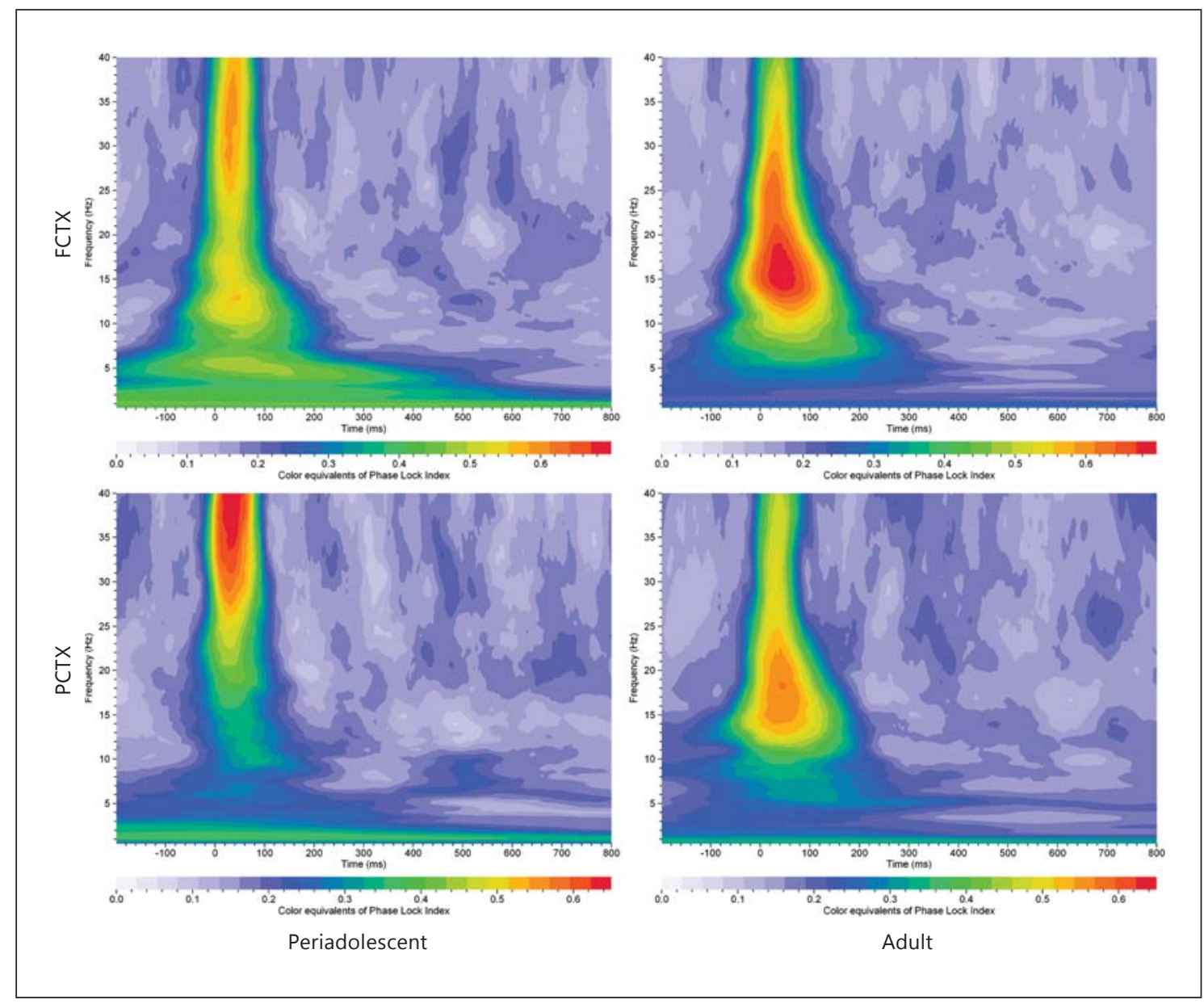

Fig. 8. Grand averages of PLI for EROs in rats (periadolescent: $n=13$, adult: $n=18$ ). Each graph depicts a time-frequency representation of phase angle synchrony values in periadolescent and adult rats following the infrequent (target) tone in the 2 electrode locations (FCTX, PCTX). In each graph, frequency (in hertz) is presented on the $\mathrm{y}$-axis and time ROIs on the $\mathrm{x}$-axis (in milliseconds). PLI is presented as color equivalents as indicated on the bar at the bottom of each graph. tential to index information processing changes during development. A body of knowledge is beginning to emerge that suggests that the phase locking of frequencyspecific, neuro-oscillatory activity within and between neural assemblies may underlie the processes whereby the brain organizes and communicates information [22, $33,77-79]$. Phase locking of EROs represents a methodology whereby neuronal synchrony can be quantified and compared among experimental conditions in both humans and animals, providing thereby a translatable measure with which to explore the neural basis of the behavioral changes associated with development.

EROs over the spectral range of the EEG (generally between 1 and $50 \mathrm{~Hz}$, although responses at lower and higher frequencies have also been reported [80-82]), have been suggested to underlie a number of different cognitive processes. For instance, event-related alpha oscillations have been attributed to attentional resources, semantic memory and stimulus processing [83-88], whereas beta and gamma oscillations have been suggested to be involved with sensory integrative processes [89-91]. Oscillations in the delta and theta frequency ranges have been associated with signal detection, decision making, conscious awareness, recognition memory and episodic retrieval $[29,79,84,92-96]$. It has been suggested that high-frequency oscillations (above $30 \mathrm{~Hz}$ ) reflect synchronization of neuronal ensembles that are interacting over short distances in response to primarily sensory processes $[97,98]$, whereas lower frequency oscillations (1$4 \mathrm{~Hz}$ ) are generated by synchronization of ensembles in- 
teracting at longer distances during higher cognitive processing $[99,100]$.

\section{Infrequent Tones Produce Higher Phase Locking than} Frequently Presented Tones, Independent of Task

In our study, the presentation of an auditory infrequently presented (rare/target) stimulus produced a robust and highly significant increase in phase locking of EROs compared to the frequently presented stimulus, both within and between brain areas in all frequency bands. Higher phase locking to target versus nontarget tones in a number of ERO frequency ranges has been reported previously in human subjects [101-104]. In most cases the authors ascribed the differences in phase locking to the response requirements and or salience of the stimulus. In the present study we compared responses to infrequent tones that required response (active task) to those that did not (passive task). We found that the effect of the tone characteristics (amplitude, frequency) produced more significant and robust differences in EROs than the effect of the task. We suggest that in this simple sensory paradigm the most likely explanation of this finding is that the results observed represent a change in neural state associated with attending to a more novel, possibly environmentally relevant noise rather than to any task requirements or salience. These findings are consistent with a previous study that evaluated phase locking of EROs using a complex motor-learning task [105]. In that task, long-range theta phase coherence was stronger in the novel condition compared to learned sequences, independent of task difficulty. The authors interpreted those findings as a reflection of an increase in the amount of sensory information necessary to integrate novel sequences compared to learned sequences. Our studies demonstrate that changes in the stimulus characteristics in simple auditory tasks can also produce widespread changes in phase locking over a number of brain areas in the full range of the EEG frequencies $(1-50 \mathrm{~Hz})$. It has been suggested that the processing of sensory information, such as those used in our simple auditory task, is primarily guided by automatic 'bottom-up' processes that do not require as much mental processing [106]. Such effects may be mediated by mesencephalic reticular activation of cortical activity [107].

\section{Developmental Findings in ERO Energy and Phase \\ Locking in Humans and Rats}

The main goal of the present study was to investigate the effects of periadolescent to young adult development on energy and phase locking of EROs within and between brain areas in order to identify electrophysiological indices of brain development that occur in both rats and humans. Although a number of studies have presented data suggesting that phase locking of EROs is correlated with various cognitive functions, fewer studies have applied this methodology in translational studies in rodents. In the present study, developmental differences consisting of significantly higher ERO energy in all frequency ranges (delta, theta, alpha, beta) in all three electrode sites (FZ, $\mathrm{CZ}, \mathrm{PZ}$ ) for both the frequently presented tone and the infrequently presented (target) tone were found in the periadolescent humans compared to the adults. Similar developmental differences were found in periadolescent rats compared to adult rats in all frequency ranges and both electrode sites (FCTX, PCTX), except for beta frequencies in the FCTX. It has long been known that EEG recordings from children are dominated by high-amplitude slower rhythms that diminish in amplitude and increase in frequency over the course of adolescence [108112] and that deviations from normal patterns have been associated with abnormal or delayed brain maturation [113]. It has also been suggested that gray matter loss or synaptic pruning may underlie these developmental changes seen in EEG amplitude over adolescent development [114]. However, it is still less clear how such changes in EEG spectral amplitude are related to cognitive changes also occurring during this time period. EEG spectral power reflects changes in both the size and strength of the neuronal assemblies engaged in stimulus processing and also to what extent the neural ensembles are in phase synchronization $[21,115]$. Our data suggest that both the size of the neural assemblies and their degree of phase locking are changed over adolescent development.

In the present study periadolescent humans were found to have significantly lower synchrony than adults as indexed by PLI levels in a range of frequencies over all electrode sites. Periadolescent humans also had significantly lower PDLI levels (FZ-PZ) than adults in all frequency ranges. Previous studies have evaluated PLI values over development in human participants. Lower evoked gamma power and PLI in children compared to adults has been previously reported using a simple visual choice-reaction task [116]. Additionally, Yordanova et al. [104] found that in 13- to 16-year-olds gamma band response in parietal but not frontal areas were enhanced by active attending to the side of a motor target more than in 9- to 12-year-olds. These data suggest that gamma band responses may mature over the course of early adolescence. Changes in alpha responses over development 
have also been reported previously. In one study, young adults were found to have significantly lower amplitude and stronger phase locking than children in the age range of 6-11 years [101]. More recently, Muller et al. [40] have demonstrated that age differences in phase locking in the delta and theta frequency bands were higher for underattended than unattended conditions using a simple auditory oddball task. Additionally, Sander et al. [117] have reported that older adults show higher intertrial phase stability shortly after stimulus onset compared to children and younger adults using a working memory task. Early phase stability has been related to working memory performance in younger adults and high-functioning older adults [118]. Taken together, these studies suggest that phase synchronization increases over development in human subjects over a range of frequencies and task requirements.

Our studies are unique in that we were able to compare measures of phase locking over a wide range of frequency bands during periadolescent to adult development in rats and compare their responses using a similar task to humans. In our studies, both periadolescent rats and humans were found to have higher energy and lower PDLI values than the adults of their species over a wide range of frequency bands. We found that although rats had similar findings to humans on measures of PLI, the results were not as robust and only occurred in the infrequently presented tone in one frequency band. One explanation of these findings is that the rats were only evaluated in a passive task. When we compared the results of our active and passive ERP tasks in human subjects, we found that ERO energy and PDLI did not differ between tasks. However, PLI values were found to differ between the active and passive tasks with the frequently presented tone being less attended to in the active task. Taken together, these data suggest that PLI values are sensitive to task requirements and thus may have less comparative value between humans and rodents that are not performing the same task.

Reductions in phase locking and/or measures of coherence between brain areas in children compared to adults have been reported previously in human subjects [40]. It has been suggested that phase locking of EROs within a brain area (PLI) may differ from phase locking of EROs between brain areas (PDLI) in terms of both the cognitive and neuroanatomical substrates of the effects. Local phase synchronization most likely reflects maturation in inhibitory-excitatory dynamics within local circuits that may be influenced by such processes as synaptic pruning and local structural reorganization $[5,11]$. Syn-

Phase Locking Increases during

Adolescence chronization between brain areas may rely on communication between brain areas that are influenced by such factors as maturation of white matter during development [15]. Vakorin et al. [119] and Thatcher et al. [120, 121] have suggested that increased integration between distributed neuronal populations is the key factor contributing to the 'increased complexity' of brain signals that occurs during development. They have further suggested that over development less information is processed locally and more information is processed over distributed circuits in the brain [119]. Our study suggests that the increase in synchrony between brain areas increases over development not only in human subjects but also in rodents.

One limitation of our study is the question of whether the functions of the brain areas recorded in rodents can be compared to humans. There has been much debate on the larger question of whether brain areas can be compared between species, especially whether nonprimate species have a prefrontal cortex that is homologous to humans [for review, see 122]. In fact, it has been suggested that the prefrontal cortex is present in rodents, carnivores and other orders of class Mammalia and that mammals possess a common class pattern of frontal lobe organization [123]. However, it has been also suggested that specific areas such as the dorsolateral prefrontal cortex do not have a homologue in the rat similar to that seen in primates [122]. Another limitation of our study was that brain size differences between periadolescents and adults and between species may limit interpretation of the data even though the electrode locations were corrected for size differences. In humans it has been suggested that differences in EEG amplitude between children and adults may be due to skull thickness [124]. However, this cannot be the case in the present study in the rats as all recordings were made with implanted electrodes, which eliminates the issue of skull thickness. Another limitation was that ERO comparisons between species were restricted to the use of a simple passive task and/or comparisons of nonattended tones. This may restrict the usefulness of these electrophysiological indices of development with respect to their relationship to cognitive development and/or task requirements. However, recent studies using measures of multivariate pattern classification analysis to examine maturation in task-induced brain activation and in functional connectivity during adolescence have found that functional brain maturation in adolescence is driven by a common process across cognitive tasks as opposed to being task specific [125]. The authors further proposed that brain connectivity changes over the course of adoles- 
cence affect brain functionality at a basic level that is common in the simplest go/no-go task and in a complex gambling task [125]. We have concluded that it is likely that recordings from simple auditory tasks can be reasonably compared between rodents and humans, but that more complex tasks may not be comparable. However, fundamental differences that occur in brain synchrony over development may be conserved, independent of task difficulty.

\section{Conclusion}

Using a similar auditory ERP paradigm in both rats and humans, we investigated the energy and phase variability of EROs. No significant changes were found in measures of ERO energy between the frequent and infrequent tones or between the active and passive tasks in periadolescent humans. Neuronal synchrony as indexed by PLI and PDLI was significantly higher to the infrequent (target) tone compared to the frequent (nontarget) tone in all brain sites in all of the ROI time-frequency intervals. There was a smaller but significant increase in PLI but not PDLI as a function of active task requirements in periadolescent humans. Developmental differences consisting of significantly higher ERO energy in all frequency ranges (delta, theta, alpha, beta) in all three electrode sites (FZ, CZ, PZ) in the periadolescent humans compared to the adults and in periadolescent rats in all frequencies in PCTX and all but beta in FCTX compared to adult rats. Periadolescent humans were found to have significantly lower synchrony than adults as indexed by lower PLI levels in the delta and theta frequency ranges in all three electrode sites (FZ, CZ, PZ). Periadolescent humans had significantly lower PDLI levels (FZ-PZ) than adults in all frequency ranges. Periadolescent rats also had lower PLI values than adults in the alpha frequencies in PCTX and lower PDLI levels than adults in the theta, alpha and beta frequency ranges. Taken together, these findings are consistent with the hypothesis that adolescent remodeling of the brain includes decreases in energy and increases in synchrony over a wide frequency range both within and between neuronal networks and that these effects are conserved over evolution.

\section{Acknowledgments}

The authors thank Shirley Sanchez and Susan Lopez for their assistance in editing the manuscript. This study was supported in part by the NIH, National Institute on Alcoholism and Alcohol Abuse grants AA006059, AA019969 and AA010201 awarded to C.L.E.

\section{References}

1 Spear LP: Adolescent neurobehavioral characteristics, alcohol sensitivities, and intake: setting the stage for alcohol use disorders? Child Dev Perspect 2011;5:231-238.

2 Spear LP, Varlinskaya EI: Sensitivity to ethanol and other hedonic stimuli in an animal model of adolescence: implications for prevention science? Dev Psychobiol 2010;52: 236-243.

3 Johnston MV: Neurotransmitters and vulnerability of the developing brain. Brain Dev 1995; 17:301-306.

4 Lidow MS, Goldman-Rakic PS, Rakic P: Synchronized overproduction of neurotransmitter receptors in diverse regions of the primate cerebral cortex. Proc Natl Acad Sci USA 1991; 88:10218-10221.

5 Seeman P: Images in neuroscience. Brain development. X. Pruning during development. Am J Psychiatry 1999;156:168.

6 van Eden CG: The development of the rat prefrontal cortex: its size and development of connections with thalamus, spinal cord and other cortical areas; in Uylings HB, van Eden CG, DeBruin JP, Corner MA, Feenstra, MG (eds): Progress in Brain Research. Amsterdam, Elsevier Science, 1990, pp 169-183.
7 Giedd JN, Rumsey JM, Castellanos FX, Rajapakse JC, Kaysen D, Vaituzis AC, Vauss YC, Hamburger SD, Rapoport JL: A quantitative MRI study of the corpus callosum in children and adolescents. Brain Res Dev Brain Res 1996;91:274-280.

-8 Sowell ER, Thompson PM, Holmes CJ, Batth R, Jernigan TL, Toga AW: Localizing age-related changes in brain structure between childhood and adolescence using statistical parametric mapping. Neuroimage 1999;9: 587-597.

-9 Sowell ER, Thompson PM, Holmes CJ, Jernigan TL, Toga AW: In vivo evidence for postadolescent brain maturation in frontal and striatal regions. Nat Neurosci 1999;2:859861.

10 Kalsbeek A, Voorn P, Buijs RM, Pool CW, Uylings HB: Development of the dopaminergic innervation in the prefrontal cortex of the rat. J Comp Neurol 1988;269:58-72.

11 Kostovic I: Structural and histochemical reorganization of the human prefrontal cortex during perinatal and postnatal life. Prog Brain Res 1990;85:223-239.
12 Gould E, Woolf NJ, Butcher LL: Postnatal development of cholinergic neurons in the rat. I. Forebrain. Brain Res Bull 1991;27:767-789.

13 Rosenberg DR, Lewis DA: Changes in the dopaminergic innervation of monkey prefrontal cortex during late postnatal development: a tyrosine hydroxylase immunohistochemical study. Biol Psychiatry 1994;36:272-277.

14 Giedd JN: Structural magnetic resonance imaging of the adolescent brain. Ann NY Acad Sci 2004; 1021:77-85.

15 Giedd JN, Lenroot RK, Shaw P, Lalonde F, Celano M, White S, Tossell J, Addington A, Gogtay N: Trajectories of anatomic brain development as a phenotype. Novartis Found Symp 2008;289:101-112.

16 Spear LP: The adolescent brain and age-related behavioral manifestations. Neurosci Biobehav Rev 2000;24:417-463.

-17 Spear LP, Brake SC: Periadolescence: age-dependent behavior and psychopharmacological responsivity in rats. Dev Psychobiol 1983; 16:83-109.

18 Varlinskaya EI, Spear LP, Spear NE: Social behavior and social motivation in adolescent rats: role of housing conditions and partner's activity. Physiol Behav 1999;67:475-482. 
19 Ojeda SR, Skinner MK: Puberty in the rat; in 36 Criado JR, Ehlers CL: Event-related oscillaKnobil E, Neill JD (eds): Knobil and Neill's Physiology of Reproduction. Amsterdam, Elsevier, 2006, pp 2061-2126.

20 Hipp JF, Engel AK, Siegel M: Oscillatory synchronization in large-scale cortical networks predicts perception. Neuron 2011;69:387396.

21 Lachaux JP, Rodriguez E, Martinerie J, Varela FJ: Measuring phase synchrony in brain signals. Hum Brain Mapp 1999;8:194-208.

22 Sauseng P, Klimesch W: What does phase information of oscillatory brain activity tell us about cognitive processes? Neurosci Biobehav Rev 2008;32:1001-1013.

23 Basar-Eroglu C, Basar E: A compound P300 $-40 \mathrm{~Hz}$ response of the cat hippocampus. Int J Neurosci 1991;60:227-237.

24 Demiralp T, Ademoglu A, Istefanopulos Y, Basar-Eroglu C, Basar E: Wavelet analysis of oddball P300. Int J Psychophysiol 2001;39: 221-227.

- 25 Demiralp T, Ademoglu A, Comerchero M, Polich J: Wavelet analysis of P3a and P3b. Brain Topogr 2001;13:251-267.

26 Karakas S, Erzengin OU, Basar E: The genesis of human event-related responses explained through the theory of oscillatory neural assemblies. Neurosci Lett 2000;285:45-48.

27 Karakas S, Erzengin OU, Basar E: A new strategy involving multiple cognitive paradigms demonstrates that ERP components are determined by the superposition of oscillatory responses. Clin Neuropathol 2000;111:17191732.

-28 Schurmann M, Basar-Eroglu C, Kolev V, Basar E: A new metric for analyzing single-trial event-related potentials (ERPs): application to human visual P300 delta response. Neurosci Lett 1995;197:167-170.

-29 Schurmann M, Basar-Eroglu C, Kolev V, Basar E: Delta responses and cognitive processing: single-trial evaluations of human visual P300. Int J Psychophysiol 2001;39:229-239.

-30 Yordanova J, Kolev V: Brain theta response predicts P300 latency in children. Neuroreport 1996;8:277-280.

- 31 Basar E, Basar-Eroglu C, Karakas S, Schurmann M: Brain oscillations in perception and memory. Int J Psychophysiol 2000;35:95-124.

- 32 Begleiter H, Porjesz B: Genetics of human brain oscillations. Int J Psychophysiol 2006; 60:162-171.

33 Roach BJ, Mathalon DH: Event-related EEG time-frequency analysis: an overview of measures and an analysis of early gamma band phase locking in schizophrenia. Schizophr Bull 2008;34:907-926.

34 Basar E: EEG Brain Dynamics: Relation between EEG and Brain Evoked Potentials. Amsterdam, Elsevier/North-Holland Biomedical Press, 1980.

-35 Makeig S, Westerfield M, Jung TP, Enghoff S, Townsend J, Courchesne E, Sejnowski TJ: Dynamic brain sources of visual evoked responses. Science 2002;295:690-694. tions as risk markers in genetic mouse models of high alcohol preference. Neuroscience 2009; 163:506-523.

37 Criado JR, Ehlers CL: Event-related oscillations in the parietal cortex of adult alcoholpreferring $(\mathrm{P})$ and alcohol-nonpreferring rats (NP). Alcohol 2010;44:335-342.

38 Criado JR, Ehlers CL: Effects of adolescent ethanol exposure on event-related oscillations (EROs) in the hippocampus of adult rats. Behav Brain Res 2010;210:164-170.

39 Ehlers CL, Criado JR: Event-related oscillations in mice: effects of stimulus characteristics. J Neurosci Methods 2009;181:52-57.

40 Muller V, Gruber W, Klimesch W, Lindenberger U: Lifespan differences in cortical dynamics of auditory perception. Dev Sci 2009; 12:839-853.

41 Brinkman MJ, Stauder JE: The development of passive auditory novelty processing. Int J Psychophysiol 2008;70:33-39.

42 Ehlers CL, Garcia-Andrade C, Wall TL, Sobel DF, Phillips E: Determinants of P3 amplitude and response to alcohol in Native American Mission Indians. Neuropsychopharmacology 1998; 18:282-292.

43 Schuckit MA: Subjective responses to alcohol in sons of alcoholics and control subjects. Arch Gen Psychiatry 1984;41:879-884.

44 Schuckit MA, Gold EO: A simultaneous evaluation of multiple markers of ethanol/placebo challenges in sons of alcoholics and controls. Arch Gen Psychiatry 1988;45:211-216.

45 American Psychiatric Association: Diagnostic and Statistical Manual of Mental Disorders (DSM-III). Washington, American Psychiatric Association, 1980.

46 Ehlers CL, Phillips E, Parry BL: Electrophysiological findings during the menstrual cycle in women with and without late luteal phase dysphoric disorder: relationship to risk for alcoholism? Biol Psychiatry 1996;39:720-732.

47 Ehlers CL, Wills DN, Havstad J: Ethanol reduces the phase locking of neural activity in human and rodent brain. Brain Res 2012; 1450:67-79.

48 Kaneko WM, Ehlers CL, Philips EL, Riley EP: Auditory event-related potentials in fetal alcohol syndrome and Down's syndrome children. Alcohol Clin Exp Res 1996;20:35-42.

49 Ehlers CL, Wall TL, Garcia-Andrade C, Phillips E: Auditory P3 findings in Mission Indian youth. J Stud Alcohol 2001;62:562-570.

50 Ehlers CL, Wall TL, Garcia-Andrade C, Phillips E: Effects of age and parental history of alcoholism on EEG findings in Mission Indian children and adolescents. Alcohol Clin Exp Res 2001;25:672-679.

51 Ehlers CL, Wall TL, Garcia-Andrade C, Phillips E: EEG asymmetry: relationship to mood and risk for alcoholism in Mission Indian youth. Biol Psychiatry 2001;50:129-136.
52 Ehlers CL, Wall TL, Garcia-Andrade C, Phillips E: Visual P3 findings in Mission Indian youth: relationship to family history of alcohol dependence and behavioral problems. Psychiatry Res 2001;105:67-78.

53 Wall TL, Ehlers CL: Acute effects of alcohol on P300 in Asians with different ALDH2 genotypes. Alcohol Clin Exp Res 1995;19:617622.

54 Ehlers CL, Havstad J, Prichard D, Theiler J: Low doses of ethanol reduce evidence for nonlinear structure in brain activity. J Neurosci 1998; 18:7474-7486.

55 Gabor D: Theory of communication. J Inst Elec Eng 1946;93:429-457.

56 Stockwell RG, Mansinha L, Lowe RP: Localization of the complex spectrum: the $S$ transform. IEEE Trans Signal Process 1996;44: 998-1001.

57 Jones KA, Porjesz B, Almasy L, Bierut L, Goate A, Wang JC, Dick DM, Hinrichs A, Kwon J, Rice JP, Rohrbaugh J, Stock H, Wu W, Bauer LO, Chorlian DB, Crowe RR, Edenberg HJ, Foroud T, Hesselbrock V, Kuperman S, Nurnberger J Jr, O'Connor SJ, Schuckit MA, Stimus AT, Tischfield JA, Reich T, Begleiter $\mathrm{H}$ : Linkage and linkage disequilibrium of evoked EEG oscillations with CHRM2 receptor gene polymorphisms: implications for human brain dynamics and cognition. Int J Psychophysiol 2004;53:75-90.

58 Schack B, Klimesch W: Frequency characteristics of evoked and oscillatory electroencephalic activity in a human memory scanning task. Neurosci Lett 2002;331:107-110.

-59 Brunner C, Graimann B, Huggins JE, Levine SP, Pfurtscheller G: Phase relationships between different subdural electrode recordings in man. Neurosci Lett 2005;375:69-74.

60 Huttenlocher PR: Synaptic density in human frontal cortex - developmental changes and effects of aging. Brain Res 1979;163:195-205.

61 Huttenlocher PR, de Court, Garey LJ, Van der LH: Synaptic development in human cerebral cortex. Int J Neurol 1982;16-17:144-154.

62 Yakovlev P, Lecours A: The myelogenetic cycles of regional maturation of the brain; in Minkowski A (ed): Regional Development of the Brain in Early Life: a symposium organized by the Council for International Organizations of Medical Sciences (established under the joint auspices of UNESCO and WHO) and by the Délégation générale à la recherche scientifique et technique. Oxford, Blackwell, 1967, pp 3-70.

63 Cragg BG: The density of synapses and neurons in normal, mentally defective ageing human brains. Brain 1975;98:81-90.

64 Changeux JP, Danchin A: Selective stabilisation of developing synapses as a mechanism for the specification of neuronal networks. Nature 1976;264:705-712.

65 Low LK, Cheng HJ: Axon pruning: an essential step underlying the developmental plasticity of neuronal connections. Philos Trans R Soc Lond B Biol Sci 2006;361:1531-1544.
Phase Locking Increases during

Adolescence
Dev Neurosci 2014;36:175-195

DOI: $10.1159 / 000358484$ 
-66 Petanjek Z, Judas M, Simic G, Rasin MR, Uylings HB, Rakic P, Kostovic I: Extraordinary neoteny of synaptic spines in the human prefrontal cortex. Proc Natl Acad Sci USA 2011;108:13281-13286.

67 Somerville LH, Casey BJ: Developmental neurobiology of cognitive control and motivational systems. Curr Opin Neurobiol 2010;20: 236-241.

68 Wetherill R, Tapert SF: Adolescent brain development, substance use, and psychotherapeutic change. Psychol Addict Behav 2012;27: 393-402.

69 Paus T: Growth of white matter in the adolescent brain: myelin or axon? Brain Cogn 2010; 72:26-35.

70 Blakemore SJ: Imaging brain development: the adolescent brain. Neuroimage 2012;61: 397-406.

71 Giedd JN: The teen brain: insights from neuroimaging. J Adolesc Health 2008;42:335343.

-72 Fair DA, Cohen AL, Power JD, Dosenbach NU, Church JA, Miezin FM, Schlaggar BL, Petersen SE: Functional brain networks develop from a 'local to distributed' organization. PLoS Comput Biol 2009;5:e1000381.

-73 Kelly AM, Di MA, Uddin LQ, Shehzad Z, Gee DG, Reiss PT, Margulies DS, Castellanos FX, Milham MP: Development of anterior cingulate functional connectivity from late childhood to early adulthood. Cereb Cortex 2009; 19:640-657.

-74 Power JD, Fair DA, Schlaggar BL, Petersen SE: The development of human functional brain networks. Neuron 2010;67:735-748.

-75 Vogel AC, Power JD, Petersen SE, Schlaggar BL: Development of the brain's functional network architecture. Neuropsychol Rev 2010;20:362-375.

76 Lindenberger U, Li SC, Backman L: Delineating brain-behavior mappings across the lifespan: substantive and methodological advances in developmental neuroscience. Neurosci Biobehav Rev 2006;30:713-717.

-77 Basar E, Basar-Eroglu C, Karakas S, Schurmann M: Oscillatory brain theory: a new trend in neuroscience. IEEE Eng Med Biol Mag 1999;18:56-66.

-78 Basar E, Demiralp T, Schurmann M, BasarEroglu C, Ademoglu A: Oscillatory brain dynamics, wavelet analysis, and cognition. Brain Lang 1999;66:146-183.

-79 Basar E, Basar-Eroglu C, Karakas S, Schurmann M: Are cognitive processes manifested in event-related gamma, alpha, theta and delta oscillations in the EEG? Neurosci Lett 1999; 259:165-168.

80 Curio G, Mackert BM, Burghoff M, Koetitz R, Abraham-Fuchs K, Harer W: Localization of evoked neuromagnetic $600 \mathrm{~Hz}$ activity in the cerebral somatosensory system. Electroencephalogr Clin Neurophysiol 1994;91:483487.
81 Monto S, Palva S, Voipio J, Palva JM: Very slow EEG fluctuations predict the dynamics of stimulus detection and oscillation amplitudes in humans. J Neurosci 2008;28:82688272.

82 Xiang J, Liu Y, Wang Y, Kotecha R, Kirtman EG, Chen Y, Huo X, Fujiwara H, Hemasilpin N, Degrauw T, Rose D: Neuromagnetic correlates of developmental changes in endogenous high-frequency brain oscillations in children: a wavelet-based beamformer study. Brain Res 2009;1274:28-39.

83 Basar E, Yordanova J, Kolev V, Basar-Eroglu $\mathrm{C}$ : Is the alpha rhythm a control parameter for brain responses? Biol Cybern 1997;76:471480.

84 Klimesch W, Schimke H, Schwaiger J: Episodic and semantic memory: an analysis in the EEG theta and alpha band. Electroencephalogr Clin Neurophysiol 1994;91:428441.

85 Klimesch W, Doppelmayr M, Schimke H, Ripper B: Theta synchronization and alpha desynchronization in a memory task. Psychophysiology 1997;34:169-176.

86 Klimesch W, Doppelmayr M, Pachinger T, Ripper B: Brain oscillations and human memory: EEG correlates in the upper alpha and theta band. Neurosci Lett 1997;238:9-12.

87 Klimesch W, Sauseng P, Hanslmayr S: EEG alpha oscillations: the inhibition-timing hypothesis. Brain Res Rev 2007;53:63-88.

88 Klimesch W: Evoked alpha and early access to the knowledge system: the P1 inhibition timing hypothesis. Brain Res 2011;1408:52-71.

89 Basar E, Basar-Eroglu C, Karakas S, Schurmann M: Gamma, alpha, delta, and theta oscillations govern cognitive processes. Int $\mathrm{J}$ Psychophysiol 2001;39:241-248.

90 Basar E, Schurmann M, Demiralp T, BasarEroglu C, Ademoglu A: Event-related oscillations are 'real brain responses' - wavelet analysis and new strategies. Int J Psychophysiol 2001;39:91-127.

-91 Schurmann M, Basar-Eroglu C, Basar E: Gamma responses in the EEG: elementary signals with multiple functional correlates. Neuroreport 1997;8:531-534.

-92 Basar E, Schurmann M, Basar-Eroglu C, Demiralp T: Selectively distributed gamma band system of the brain. Int J Psychophysiol 2001;39:129-135.

93 Basar E, Schurmann M, Sakowitz O: The selectively distributed theta system: functions. Int J Psychophysiol 2001;39:197-212.

94 Doppelmayr M, Klimesch W, Schwaiger J, Auinger P, Winkler T: Theta synchronization in the human EEG and episodic retrieval. Neurosci Lett 1998;257:41-44.

95 Gevins A, Smith ME, Leong H, McEvoy L, Whitfield S, Du R, Rush G: Monitoring working memory load during computer-based tasks with EEG pattern recognition methods. Hum Factors 1998;40:79-91.
$\$ 96$ Klimesch W, Doppelmayr M, Stadler W, Pollhuber D, Sauseng P, Rohm D: Episodic retrieval is reflected by a process specific increase in human electroencephalographic theta activity. Neurosci Lett 2001;302:49-52.

97 Bressler SL, Freeman WJ: Frequency analysis of olfactory system EEG in cat, rabbit, and rat. Electroencephalogr Clin Neurophysiol 1980;50:19-24.

98 Ohl FW, Deliano M, Scheich H, Freeman WJ: Early and late patterns of stimulus-related activity in auditory cortex of trained animals. Biol Cybern 2003;88:374-379.

-99 Kopell N, Ermentrout GB, Whittington MA, Traub RD: Gamma rhythms and beta rhythms have different synchronization properties. Proc Natl Acad Sci USA 2000;97: 1867-1872.

100 Lubar JF: Neocortical dynamics: implications for understanding the role of neurofeedback and related techniques for the enhancement of attention. Appl Psychophysiol Biofeedback 1997;22:111-126.

101 Yordanova J, Kolev V: Alpha response system in children: changes with age. Int J Psychophysiol 1997;26:411-430.

102 Yordanova J, Kolev V, Demiralp T: Effects of task variables on the amplitude and phaselocking of auditory gamma band responses in human. Int J Neurosci 1997;92:241-258.

103 Muller V, Anokhin AP: Neural synchrony during response production and inhibition. PLoS One 2012;7:e38931.

104 Yordanova J, Kolev V, Heinrich H, Woerner W, Banaschewski T, Rothenberger A: Developmental event-related gamma oscillations: effects of auditory attention. Eur J Neurosci 2002;16:2214-2224.

105 Sauseng P, Klimesch W, Gruber WR, Hanslmayr S, Freunberger R, Doppelmayr M: Are event-related potential components generated by phase resetting of brain oscillations? A critical discussion. Neuroscience 2007; 146:1435-1444.

106 Klimesch W, Sauseng P, Hanslmayr S, Gruber W, Freunberger R: Event-related phase reorganization may explain evoked neural dynamics. Neurosci Biobehav Rev 2007;31: 1003-1016.

107 Munk MH, Roelfsema PR, Konig P, Engel $\mathrm{AK}$, Singer W: Role of reticular activation in the modulation of intracortical synchronization. Science 1996;272:271-274

108 Boord PR, Rennie CJ, Williams LM: Integrating 'brain' and 'body' measures: correlations between EEG and metabolic changes over the human lifespan. J Integr Neurosci 2007;6:205-218.

109 Clarke AR, Barry RJ, McCarthy R, Selikowitz M: Age and sex effects in the EEG: development of the normal child. Clin Neurophysiol 2001;112:806-814.

110 Gasser T, Verleger R, Bacher P, Sroka L: Development of the EEG of school-age children and adolescents. I. Analysis of band power. Electroencephalogr Clin Neurophysiol 1988;69:91-99. 
$\$ 11$ Klimesch W: EEG alpha and theta oscillations reflect cognitive and memory performance: a review and analysis. Brain Res Brain Res Rev 1999;29:169-195.

-112 Rodriguez-Martinez E, Barriga-Paulino C, Zapata M, Chinchilla C, Lopez-Jimenez A, Gomez C: Narrow band quantitative and multivariate electroencephalogram analysis of peri-adolescent period. BMC Neurosci 2012;13:104

-113 John ER, Ahn H, Prichep L, Trepetin M, Brown D, Kaye H: Developmental equations for the electroencephalogram. Science 1980; 210:1255-1258.

114 Whitford TJ, Rennie CJ, Grieve SM, Clark CR, Gordon E, Williams LM: Brain maturation in adolescence: concurrent changes in neuroanatomy and neurophysiology. Hum Brain Mapp 2007;28:228-237.

115 Tass P, Rosenblum MG, Weule J, Kurths J, Pikovsky A, Volkmann J, Schnitzler A, Freund HJ: Detection of $n: m$ phase locking from nosiy data: application to magnetoencephalography. Phys Rev Lett 1998;81: 3291-3294.
116 Werkle-Bergner M, Shing YL, Muller V, Li SC, Lindenberger U: EEG gamma-band synchronization in visual coding from childhood to old age: evidence from evoked power and inter-trial phase locking. Clin Neurophysiol 2009;120:1291-1302.

117 Sander MC, Werkle-Bergner M, Lindenberger U: Amplitude modulations and intertrial phase stability of alpha-oscillations differentially reflect working memory constraints across the lifespan. Neuroimage 2012;59:646-654.

118 Werkle-Bergner M, Freunberger R, Sander MC, Lindenberger U, Klimesch W: Interindividual performance differences in younger and older adults differentially relate to amplitude modulations and phase stability of oscillations controlling working memory contents. Neuroimage 2012;60:71-82.

119 Vakorin VA, Lippe S, McIntosh AR: Variability of brain signals processed locally transforms into higher connectivity with brain development. J Neurosci 2011;31: 6405-6413.
20 Thatcher RW, North D, Biver C: EEG and intelligence: relations between EEG coherence, EEG phase delay and power. Clin Neurophysiol 2005;116:2129-2141.

121 Thatcher RW, North DM, Biver CJ: Development of cortical connections as measured by EEG coherence and phase delays. Hum Brain Mapp 2008;29:1400-1415.

122 Preuss TM: Do rats have prefrontal cortex? The Rose-Woolsey-Akert program reconsidered. J Cogn Neurosci 1995;7:1-24.

123 Kolb B, Whishaw IQ: Fundamentals of Human Neuropsychology, ed 3. New York, Freeman, 1990.

124 Frodl T, Meisenzahl EM, Muller D, Leinsinger G, Juckel G, Hahn K, Moller HJ, Hegerl $\mathrm{U}$ : The effect of the skull on event-related P300. Clin Neurophysiol 2001;112:17731776.

125 Keulers EH, Goulas A, Jolles J, Stiers P: Maturation of task-induced brain activation and long-range functional connectivity in adolescence revealed by multivariate pattern classification. Neuroimage 2012;60:12501265. 